\title{
Characterizing KIF16B in Neurons Reveals a Novel Intramolecular "Stalk Inhibition" Mechanism That Regulates Its Capacity to Potentiate the Selective Somatodendritic Localization of Early Endosomes
}

\author{
${ }^{\circledR}$ Atena Farkhondeh, ${ }^{1}$ Shinsuke Niwa, ${ }^{1}$ Yosuke Takei, ${ }^{1}$ and Nobutaka Hirokawa ${ }^{1,2}$ \\ 'Department of Molecular and Cell Biology and Department of Molecular Structure and Dynamics, Graduate School of Medicine, University of Tokyo, \\ Tokyo 113-0033, Japan, and ${ }^{2}$ Center of Excellence in Genome Medicine Research, King Abdulaziz University, Jeddah 21589, Saudi Arabia
}

\begin{abstract}
An organelle's subcellular localization is closely related to its function. Early endosomes require localization to somatodendritic regions in neurons to enable neuronal morphogenesis, polarized sorting, and signal transduction. However, it is not known how the somatodendritic localization of early endosomes is achieved. Here, we show that the kinesin superfamily protein 16B (KIF16B) is essential for the correct localization of early endosomes in mouse hippocampal neurons. Loss of KIF16B induced the aggregation of early endosomes and perturbed the trafficking and functioning of receptors, including the AMPA and NGF receptors. This defect was rescued by KIF16B, emphasizing the critical functional role of the protein in early endosome and receptor transport. Interestingly, in neurons expressing a KIF16B deletion mutant lacking the second and third coiled-coils of the stalk domain, the early endosomes were mistransported to the axons. Additionally, the binding of the motor domain of KIF16B to microtubules was inhibited by the second and third coiled-coils (inhibitory domain) in an ATP-dependent manner. This suggests that the intramolecular binding we find between the inhibitory domain and motor domain of KIF16B may serve as a switch to control the binding of the motor to microtubules, thereby regulating KIF16B activity. We propose that this novel autoregulatory "stalk inhibition" mechanism underlies the ability of KIF16B to potentiate the selective somatodendritic localization of early endosomes.
\end{abstract}

Key words: early endosome; KIF16B; neurons; receptor trafficking; stalk inhibition

\section{Introduction}

Neurons are highly polarized cells with a long axon and short dendrites (Nicholls, 2001). Commensurate with specific roles of axons and dendrites, the localization of organelles and proteins within these structures is differentially regulated. Motor proteins determine the subcellular localization of many organelles in neurons (Hirokawa et al., 2010). The kinesin superfamily proteins (KIFs) are microtubule and ATP-dependent motor proteins, most members of which transport cargoes to the microtubules plus-end (Vale, 2003; Verhey and Hammond, 2009; Hirokawa et al., 2010). Defects in motor transport are associated with many

\footnotetext{
Received Oct. 13, 2014; revised Jan. 20, 2015; accepted Feb. 19, 2015.

Author contributions: A.F., S.N., Y.T., and N.H. designed research; A.F., S.N., and Y.T. performed research; A.F. contributed unpublished reagents/analytic tools; A.F., S.N., Y.T., and N.H. analyzed data; A.F., S.N., Y.T., and N.H. wrote the paper.

This work was supported by the Ministry of Education, Culture, Sports, Science and Technology of Japan Grantin-Aid for Specially Promoted Research to N.H. We thank the members of the N.H. laboratory for assistance and valuable discussions; Y. Noda, T. Ogawa, Y. Kanai, Y. Tanaka, H. Miki, R. Nitta, H. Yajima, K. Nakajima, K. Mitsumori, and X. Fang for technical assistance; and H. Sato, H. Fukuda, and T. Akamatsu for help.

The authors declare no competing financial interests.

Correspondence should be addressed to Dr. Nobutaka Hirokawa, Department of Molecular and Cell Biology, Graduate School of Medicine, University of Tokyo, 7-3-1 Hongo, Bunkyo-ku, Tokyo 113-0033, Japan. E-mail: hirokawa@m.u-tokyo.ac.jp.

DOI:10.1523/JNEUROSCI.4240-14.2015

Copyright $\odot 2015$ the authors $\quad 0270-6474 / 15 / 355067-20 \$ 15.00 / 0$
}

diseases, including neurodegeneration, cancer, and developmental defects (Salinas et al., 2008; Sarli and Giannis, 2008; Wood et al., 2008; Gerdes et al., 2009). The intraneuronal localization of some organelles, such as mitochondria, synaptic vesicle precursors, and RNA-protein complexes, are regulated by KIFs (Nangaku et al., 1994; Okada et al., 1995; Zhao et al., 2001; Kanai et al., 2004; Cai et al., 2005; Glater et al., 2006; Niwa et al., 2008). The appropriate localization of kinesin motors and their cargoes is critical for cell function.

The early endosome (EE) is a membrane-bound organelle that serves as a hub for receptor sorting, trafficking, signal transduction, and protein degradation (Hoogenraad et al., 2010; Lasiecka et al., 2010). EEA1-positive EEs are mainly localized in the somatodendritic region of neurons (Wilson et al., 2000). When axonal proteins are missorted to dendrites, they are removed from the dendritic plasma membrane by endocytosis, transported to somatodendritic EEs, and re-sorted to axons (Sampo et al., 2003). However, the molecular mechanism determining the specific somatodendritic localization of EEs remains unknown.

KIF16B, a member of the kinesin-3 family, was identified as the plus-end motor protein that transports Rab5-positive EEs and Rab14-positive vesicles in non-neuronal cells (Hoepfner et al., 2005; Ueno et al., 2011). KIF16B has a conserved motor do- 

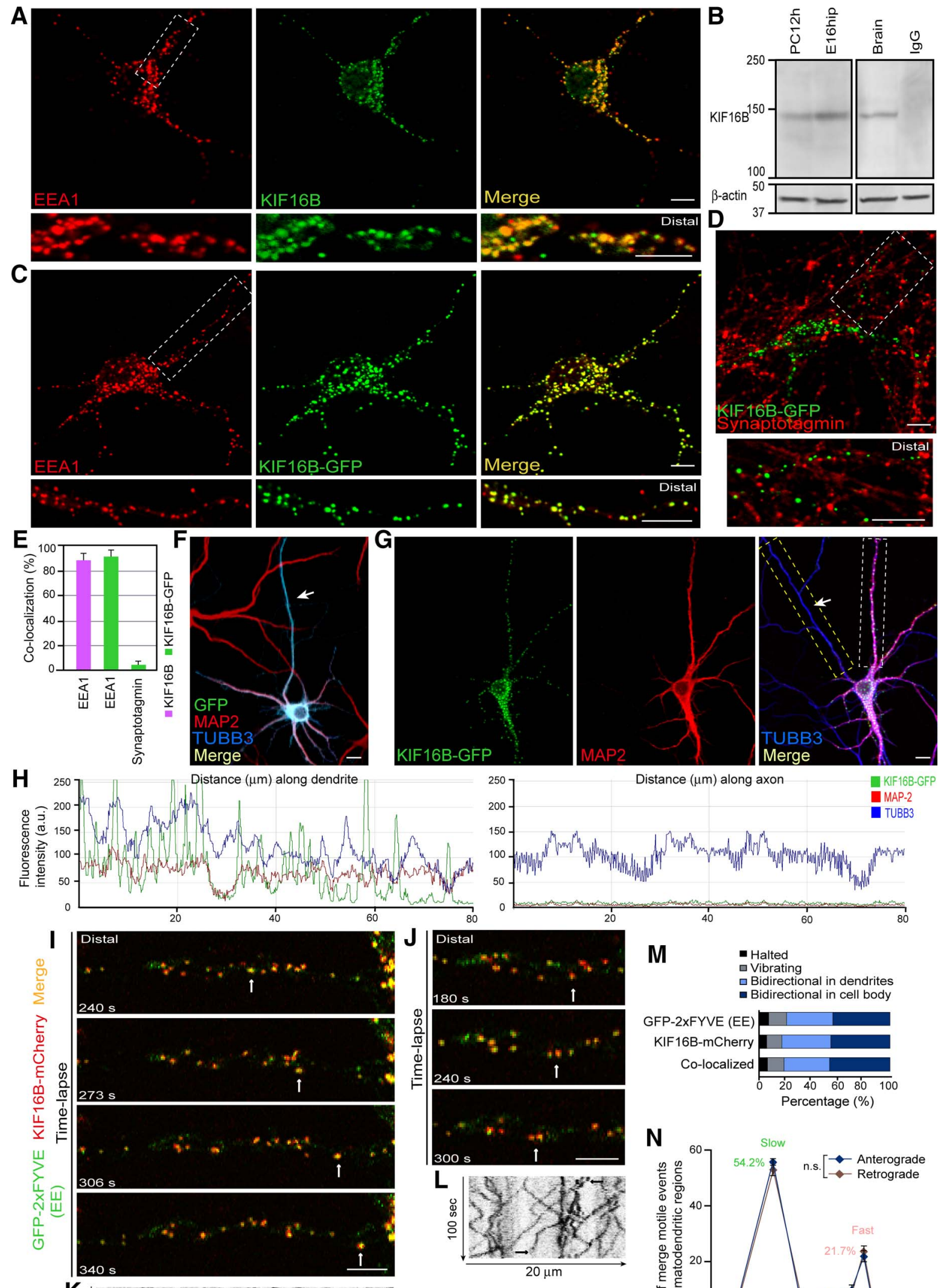

Distance $(\mu \mathrm{m})$ along axon

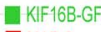

MAP-2

TUBB3
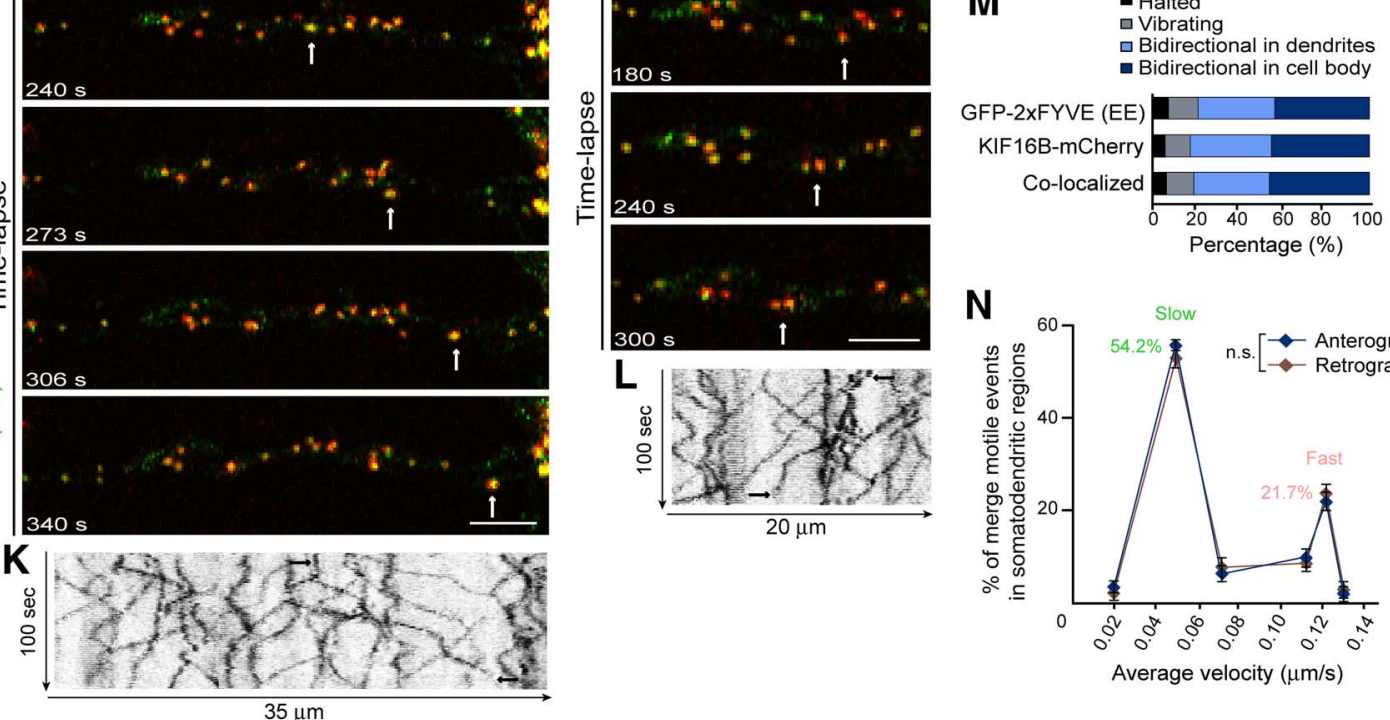

N

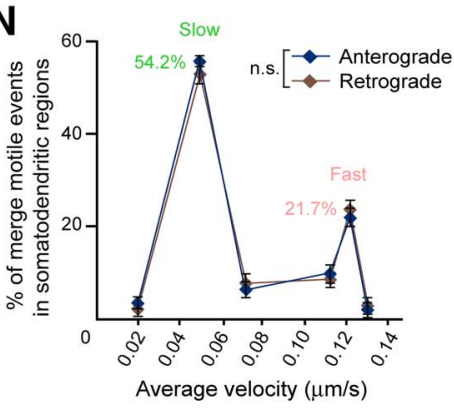




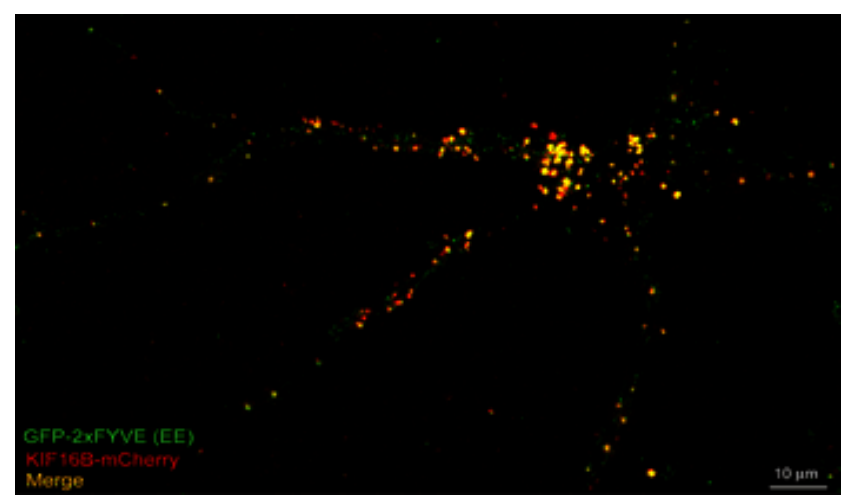

Movie 1. Dynamics of colocalized KIF16B and early endosomes in neurons. KIF16B-mCherry (red) and GFP-2xFYVE (green) were cotransfected into hippocampal neurons and observed using an LSM710 Duo confocal laser-scanning microscope (Carl Zeiss). The movie shows colocalized KIF16B and EE bidirectional movements in the somatodendritic region. The cell body of the neuron is on the right, and the dendrites are on the top left. The time-lapse covers $5 \mathrm{~min}$, with images acquired every $2 \mathrm{~s}$. Scale bars, $10 \mu \mathrm{m}$.

main, three coiled-coils in the stalk domain, and a PX domain. In HeLa cells, KIF16B regulates the recycling and degradation of EGF-receptors by controlling the localization and function of EEs (Hoepfner et al., 2005). A structural study has shown that the PX domain binds directly to phosphatidylinositol-3-phosphate (PI3P) at the endosomal membrane (Blatner et al., 2007). Introducing a point mutation that abolishes the binding to PI3P changes the localization of KIF16B. In mouse embryonic fibroblasts, KIF16B transports FGF-receptor-carrying vesicles from the Golgi to the plasma membrane via EEs (Ueno et al., 2011). KIF16B is also reportedly involved in tubule formation and fission by inducing early endosomal fusion (Skjeldal et al., 2012). Another study showed that KIF16B mediates the transcytosis of transferrin receptors to apical recycling endosomes in epithelial cells (Perez Bay et al., 2013). A recent paper suggested that kinesin-3 motors undergo cargo-mediated dimerization around the neck coil segment, which results in processive motion (Soppina et al., 2014).

\section{$\leftarrow$}

Figure 1. KIF16B transports early endosomes in somatodendritic areas of neurons. $\boldsymbol{A}$, Cultured hippocampal neurons immunostained with anti-KIF16B and anti-EEA1 antibodies. $\boldsymbol{B}$, Representative Western blot showing the specificity of the generated anti-KIF16B antibody in brain, hippocampal neurons (E16), and PC12 cells. $\beta$-Actin was used as a loading control. C-E, KIF16B-GFP was expressed in hippocampal neurons and stained with an anti-EEA1 (C) and an anti-synaptotagmin $(\boldsymbol{D})$ antibody. Higher-magnification images of the areas indicated in $\boldsymbol{A}, \boldsymbol{C}, \boldsymbol{D}$ are found below their respective panels. $\boldsymbol{A}, \boldsymbol{C}$, Images highlighting the colocalization of KIF16B with EEA1 along dendrites. Scale bars, $10 \mu \mathrm{m}$. $\boldsymbol{E}$, Quantification of endogenous KIF16B and KIF16B-GFP colocalization with EEA1 and synaptotagmin. Colocalization was quantified using a pixel-by-pixel correlation between the green and red channels with ImageJ software. $\boldsymbol{F}-\boldsymbol{H}$, Expression of KIF16B in somatodendritic regions of neurons. GFP control $(\boldsymbol{F})$ and KIF16B-GFPpositive neurons $(\boldsymbol{G})$ stained with anti- $\beta 3$ tubulin and anti-MAP2, which are neuron and dendrite markers, respectively. White arrows indicate axons. $\boldsymbol{H}$, Representative fluorescence profiles along an axon and dendrite, shown in dotted yellow and white boxes in $\mathbf{G}$, indicate that KIF16B-GFP is absent from axons and present in dendrites. Fluorescence profiles were scored using Carl Zeiss LSM image software. Scale bars, $10 \mu \mathrm{m}$. I-N, Analysis of KIF16B and EE dynamics. $I, J$, Time-lapse images of bidirectional movement of KIF16B and the EEs along the dendrite in a representative neuron, shown in Movie 1, that expressed GFP-2xFYVE and KIF16B-mCherry. Arrows indicate some of the colabeled clusters. Scale bars, $5 \mu \mathrm{m} . \boldsymbol{K}, \boldsymbol{L}$, Kymographs showing the bidirectional motility of colocalized clusters, indicated by arrows. $M$, Classification of motility ( $p=0.96 ; \chi^{2}$ test). $\boldsymbol{N}$, Percentage of the anterograde and retrograde merged motile events in somatodendritic regions according to the average velocity. Clusters that vibrated or did not move were not counted. Values are mean \pm SD. Eighteen neurons from three independent experiments were analyzed. n.s., Not significant. See also Movie 1.
Here, using a variety of molecular and cell biology methods, we investigated the function of KIF16B in neurons. We show that the stalk domain of KIF16B brings a potential to determine the specific somatodendritic localization of EEs mediated by a novel intramolecular inhibitory mechanism.

\section{Materials and Methods}

Cloning KIF16B and construct engineering. Human KIF16B (NM_ 001199865.1) was purchased from Thermo Scientific cDNA library, and PCRed using KOD-plus DNA polymerase (Toyobo). All PCR products were cloned into pEGFP-N1, pEGFP-C1, pIRES, or pPAmCherry1-N1 (Clontech). The 3xFLAG-N1 was derived from pEGFP-N1 by replacing the GFP with a 3xFLAG tag. The 2xFYVE was generated by PCR from an HGF-regulated tyrosine kinase substrate (Riken Fantom clone B230365P04) to serve as an endosomal marker and was cloned into miRNA, pIRES, pEGFP-C1, and the pGEX-4T1 vectors. Deletion mutants were made by amplifying KIF16B nucleotides corresponding to residues 1-560, 1-643, 1-810, 1-936, 1-1085, 1-1096, 1-1116, 1117$1266,548-1266,1-810$, and $1117-1266$ ( $\Delta$ second and third coiledcoils), 809-1096, and a chimera was generated using the motor domain of KIF5C, 1-560, and the PX domain, 1117-1266, of KIF16B. All constructs were engineered by PCR and cloned into pEGFP-N1 and pEGFP-C1 vectors. L1197A/F1198A point mutations in the PX domain of full-length K1F16B (KIF16BFull) were generated using the QuikChange II Site-Directed Mutagenesis Kit (Stratagene) and cloned in pEGFP-N1.

Antibodies. Anti-KIF16B antibody was generated by immunizing rabbits with the synthetic peptide (CEFSPFFKKGVFDYSSHGTG) conjugated with keyhole limpet hemocyanin, using an Imject maleimideactivated immunogen conjugation kit (Pierce). After four injections, serum was collected and affinity-purified with antigen peptides using SulfoLink columns (Pierce). The efficiency of the generated anti-KIF16B antibody was determined using Western blotting and immunostaining. The antibodies used for immunofluorescence, Western blotting, coimmunoprecipitation, and microtubule binding assays were as follows: anti- $\beta 3$-tubulin (Sigma, 1:1000), anti-MAP2 (Abcam, 1:100), antiGM130 (BD Biosciences, 1:1000), anti-synaptotagmin (Millipore Bioscience Research Reagents, 1:500), anti-EEAI (sc-6415, Santa Cruz Biotechnology, 1:100), anti-FLAG M2 (Sigma, 1:1000), anti- $\alpha$-tubulin (Sigma, 1:1000), anti-IgG (Abcam, 1:2000), anti- $\beta$-actin (Abcam, 1:4000), anti-GFP (MBL-598, 1:2000), anti-GluR1 extracellular epitope (Santa Cruz Biotechnology, 1:200), anti-NGFR p75 extracellular epitope (Millipore, 1:1000). All HRP-conjugated antibodies were purchased from GE Healthcare and used at a dilution of 1:10,000, and all AlexaFluor-conjugated antibodies were purchased from Invitrogen and used at a dilution of 1:250.

Cell culture and immunocytochemistry. COS-7 cells were cultured in DMEM containing $10 \% \mathrm{FBS}$ at $37^{\circ} \mathrm{C}$ in a $5 \% \mathrm{CO}_{2}$ atmosphere. Primary cultured neurons were obtained from 4 to 10 embryonic hippocampi at $16 \mathrm{~d}$ postcoitum from mice of either sex and grown on LabTek four-well chambered coverslips (Nunc) containing MEM (Invitrogen) supplemented with B27 (Invitrogen) and GlutaMAX-I (Invitrogen). For immunofluorescence microscopy, neurons at 8-10 DIV were transfected using a calcium phosphate protocol described previously (Jiang and Chen, 2006) and were fixed 10-12 h after transfection with 4\% PFA in PBS, washed twice with PBS, incubated with $0.1 \%$ Triton X-100 (Sigma) for $5 \mathrm{~min}$, and blocked with $1 \%$ BSA in PBS. Cells were incubated with primary antibodies overnight at $4^{\circ} \mathrm{C}$. Incubation with Alexa-labeled secondary antibodies (Invitrogen) was performed for $30 \mathrm{~min}$ at room temperature. For all knockdown experiments, KIF16B KD, control, and rescued neurons were fixed $72 \mathrm{~h}$ after transfection. For cell surface evaluation of receptors in KIF16B KD, control, and rescued neurons, the neurons were not permeabilized after fixation because both anti-GluR1 and anti-NGFR antibodies have extracellular epitopes. However, to detect intracellular and extracellular signals of the receptors, neurons were permeabilized after fixation with $0.1 \%$ Triton X-100 in PBS buffer for 5 min at room temperature, followed by blocking as above. Other cell transfections were performed using Lipofectamine 2000 (Invitrogen). 


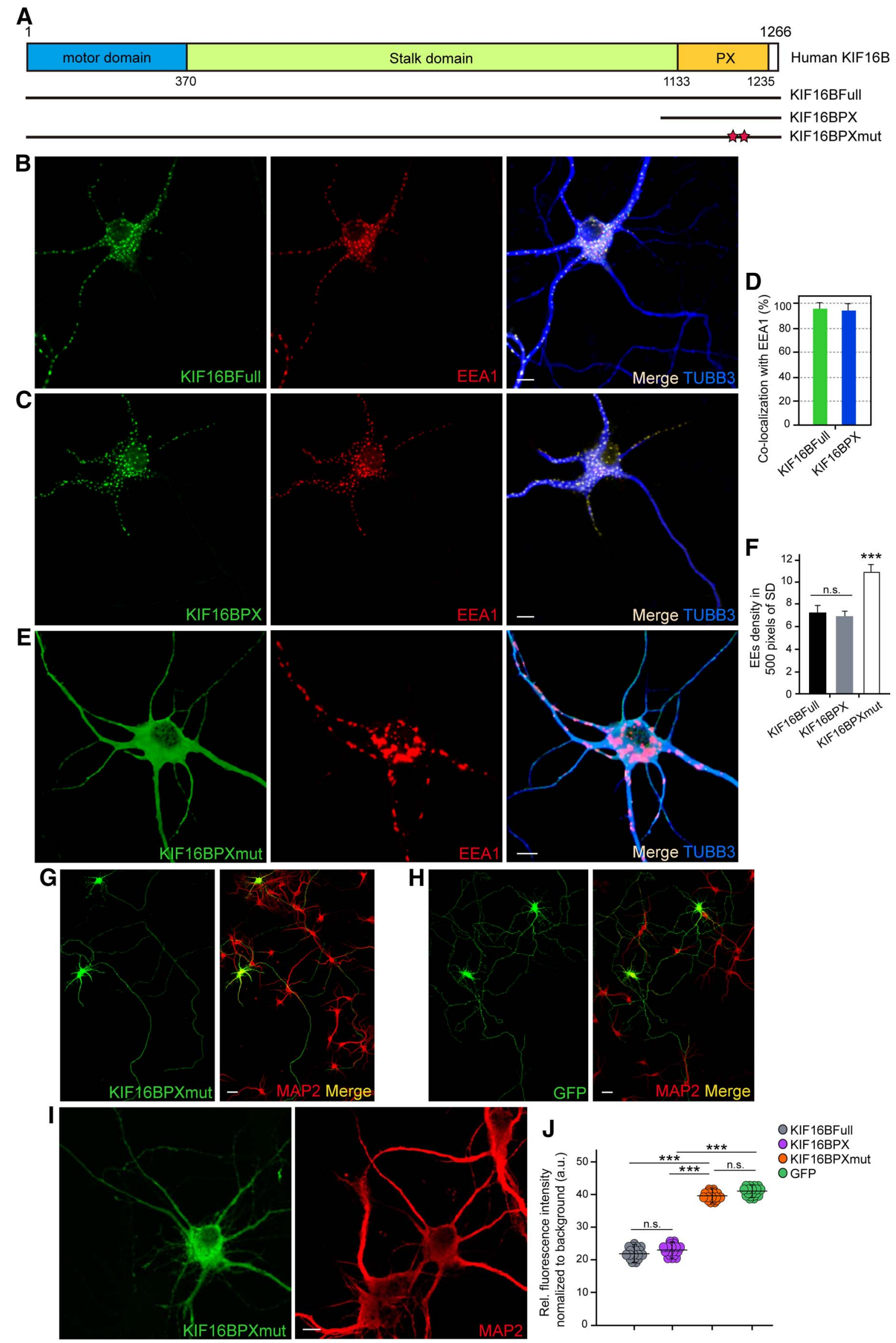


RNAi assay using microRNA. The BLOCK-iT Pol II miR RNAi Expression vector kit (Invitrogen) was used following the manufacturer's protocol. Target sequences were designed using the Invitrogen website (https://rnaidesigner.invitrogen.com/rnaiexpress/). The knockdown efficiency of three sequences was tested using Western blot analysis of hippocampal neurons $72 \mathrm{~h}$ after transfection. From these three constructs, one was selected. Generated 2xFYVE tagged with GFP was then cloned into target miRNA, as an endosomal marker and a transfection control. $\beta$-Tubulin served as a loading control in immunoblotting assays.

Cell surface protein biotinylation analysis. For cell surface protein biotinylation analysis, hippocampal neurons cultured in 6-cm-diameter dishes for $8 \mathrm{~d}$ were transfected with KIF16B-RNAi, the control construct, or KIF16B-RNAi+RNAi-resistant KIF16B and grown for $72 \mathrm{~h}$. According to the manufacturer's protocol, the cell surface proteins were biotinylated and extracted with a Cell Surface Protein Isolation kit (Pierce). Extracted proteins were then analyzed using immunoblotting. The intracellular protein $\beta$-tubulin was used as a control for transfection efficiency, and anti-KIF16B was used as a knockdown efficiency control. Quantification of protein bands was conducted using the National Institutes of Health ImageJ gel analysis software.

Electrophysiology. Whole-cell patch-clamp recordings of mEPSCs were performed on 13-16 DIV primary hippocampal cultures. During recordings, neurons were continuously perfused with an extracellular solution containing (in mM) as follows: $140 \mathrm{NaCl}, 3 \mathrm{KCl}, 2 \mathrm{CaCl}_{2}, 2 \mathrm{MgCl}_{2}, 10$ HEPES, and 20 glucose, buffered to $\mathrm{pH} 7.3$ with $\mathrm{NaOH}$. The intracellular solution present in the pipette contained (in $\mathrm{mm}$ ) the following: 115 $\mathrm{CsMeSO}_{4}, 20 \mathrm{CsCl}, 10$ HEPES, 0.6 EGTA, $2.5 \mathrm{MgCl}_{2}, 0.4 \mathrm{Na}_{3} \mathrm{GTP}, 4$ $\mathrm{Na}_{2} \mathrm{ATP}$, and 10 sodium phosphocreatine. Picrotoxin $(50 \mu \mathrm{M})$ was used to block inhibitory synaptic transmission, and $500 \mathrm{~nm}$ TTX was used to block the generation of action potentials. Recordings were acquired with an Axopatch 1D amplifier (Molecular Devices). Glass electrodes were pulled with a Sutter P-97 micropipette puller (Sutter Instruments) to a tip resistance (R) $2-3 \mathrm{M} \Omega$. Data were filtered at $1 \mathrm{kHz}$, digitized at $2 \mathrm{kHz}$, and analyzed using the Mini Analysis Program (Synaptosoft). The threshold of the mEPSC amplitude was set at $5 \mathrm{pA}$. Recordings with Rs $>20 \mathrm{M} \Omega$ and those with Rs that changed by $>20 \%$ were not included in the analysis.

Microtubule cosedimentation assay. The 1-810-pEGFP, 1-1096pEGFP, full-length pEGFP, $1-810+1117-1226$-pEGFP, and myosin Vb-pEGFP (negative control) were transfected into COS-7 cells. Fourteen hours later, the cells were lysed with PEM buffer (100 mM PIPES, 1 mm EGTA, $1 \mathrm{~mm} \mathrm{MgSO}_{4}$ containing 1\% Triton X-100 and complete protease inhibitor, Roche) and then centrifuged at 15,000 rpm for $10 \mathrm{~min}$ at $4^{\circ} \mathrm{C}$. The lysate was then supplemented with $1 \mathrm{mg} / \mathrm{ml}$ of a taxolstabilized microtubule solution, which was purified from porcine brain as previously described (Kondo et al., 1994). The mixture was incubated at room temperature for $1 \mathrm{~h}$ in the presence or absence of $1 \mathrm{~mm}$ AMP-

$\leftarrow$

Figure 2. C terminus of KIF16B acts as the early endosome binding domain. $A$, Schematic showing the constructs. Stars represent L1197A/F1198A point mutations. B-I, Mutants fused with GFP, expressed in hippocampal neurons, and then immunostained with anti-EEA1 and anti- $\beta 3$ tubulin $(\boldsymbol{B}, \boldsymbol{C}, \boldsymbol{E})$ and in samples stained with anti-MAP2 $(\boldsymbol{G}-\boldsymbol{I})$. Full-length KIF16B (KIF16BFull) (B) and (-terminal KIF16BPX (C) show a punctuate endosomal distribution pattern that colocalizes with EEs in the somatodendritic (SD) regions. D, Quantification of KIF16BFull and KIF16BPX colocalization with EEA1. Colocalization was quantified using a pixel-by-pixel correlation between the green and red channels with ImageJ software. E, KIF16B containing point mutations displays a diffuse distribution of the mutant throughout the neuron, with clustered EEs in SD regions. $F$, Statistical analysis of EE density in 500 pixels of $S D$ region indicates a significant difference in EE density between the KIF16Bmut and both KIF16BFull and KIF16BPX. G, I, KIF16B containing L1197A/F1198A point mutations in the PX domain and (H) control GFP. Both display a diffuse localization. J, Quantification of relative fluorescence intensity of KIF16BPX, KIF16BFull, KIF16BPXmut, and control GFP-transfected neurons, normalized to background signal. No significant difference was found between KIF16BPXmut and GFP control or KIF16BFull and KIF16BPXmut. Quantifications of densities $(\boldsymbol{F})$ and fluorescence mean intensities $(\boldsymbol{J})$ were performed with ImageJ software. Data are mean \pm SD. Eighteen neurons from three independent transfections were examined. ${ }^{* * *} p<0.001$ (F, Student's $t$ test; J, post hoc test). n.s., Not significant. Scale bars, $10 \mu \mathrm{m}$.
PNP and centrifuged at $50,000 \mathrm{rpm}$ for $10 \mathrm{~min}$ at $27^{\circ} \mathrm{C}$. The supernatant (S1) was stored at $4^{\circ} \mathrm{C}$ for use in further analysis. The pellet (P1) was washed with PEM and centrifuged again at 50,000 rpm for $10 \mathrm{~min}$ at $27^{\circ} \mathrm{C}$. S1 and P1 fractions were subjected to SDS-PAGE followed by Western blot analysis.

Live neuron microtubule binding assay. Mouse hippocampal neurons were cultured as described above and plated on LabTek four-well chambered coverslips (Nunc) containing MEM (Invitrogen) supplemented with B27 (Invitrogen) and GlutaMAX-I (Invitrogen), and transfected with plasmids encoding full-length pEGFP, or 1-810 + 1117-1226pEGFP. Four hours later, neurons were treated with $0.1 \mu \mathrm{g} / \mathrm{ml}$ streptolysin-O in permeabilization buffer (PB: $25 \mathrm{~mm}$ HEPES/KOH, 115 mM potassium acetate, $5 \mathrm{~mm}$ sodium acetate, $5 \mathrm{~mm} \mathrm{MgCl}_{2}, 0.5 \mathrm{~mm}$ EGTA, and $10 \mathrm{mg} / \mathrm{ml} \mathrm{BSA}$; $\mathrm{pH}$ 7.4) for $2 \mathrm{~min}$. After washing three times with PB, neurons were incubated with $\mathrm{PB}$ containing $1 \mathrm{~mm} \mathrm{AMP}-\mathrm{PNP}$ at $37^{\circ} \mathrm{C}$ in a $5 \% \mathrm{CO}_{2}$ atmosphere and monitored after $10 \mathrm{~min}$. To visualize microtubules in live neurons, a special $\mathrm{BiG}(\mathrm{GaAsP})$ detector in a Carl Zeiss LSM710 Duo laser scanning confocal microscope was used to achieve a high-resolution image.

Coimmunoprecipitation. The 1-810-3xFLAG, EGFP-809-1096 (third coiled-coil), and EGFP-1117-1226 (PX domain) were transfected into COS-7 cells. After $14 \mathrm{~h}$, cells were lysed in $10 \mathrm{~mm}$ HEPES at pH 7.4, 150 $\mathrm{mm} \mathrm{NaCl}$, and $1 \% \mathrm{NP} 40$ with a protease inhibitor mixture (Roche). Coimmunoprecipitation was performed using anti-GFP antibodies. After incubation for $1 \mathrm{~h}$ at $4^{\circ} \mathrm{C}$, protein- $\mathrm{G}$ was added and incubation continued for 1 more hour. Samples were then centrifuged at $1000 \mathrm{rpm}$ for 1 min at $4^{\circ} \mathrm{C}$ followed by three washes in lysis buffer. Input and pellet fractions were subjected to SDS-PAGE followed by Western blot analysis using anti-GFP and anti-FLAG antibodies.

GST pull-down assay. Purified GST or GST-tagged 809-1096 proteins $(10 \mu \mathrm{g})$ were preincubated with beads in lysis buffer (50 mM Tris, $\mathrm{pH} 7.4$, $150 \mathrm{~mm} \mathrm{NaCl}, 10 \mathrm{~mm} \mathrm{MgCl}$, 10\% glycerol, 1\% Triton X-100, 1 mм DTT, various protease inhibitors, and $1 \mathrm{mM}$ ATP or $1 \mathrm{~mm}$ AMP-PNP) for $1 \mathrm{~h}$ at $4^{\circ} \mathrm{C}$. Extracts of COS-7 cells transfected with various GFP-tagged 1-810, full-length, and 1117-1226 KIF16B fragments were first incubated with beads in lysis buffer for $0.5 \mathrm{~h}$. The cleared supernatants were then transferred to a new batch of beads, mixed with GST or GST-tagged 809-1096, and rotated for $2 \mathrm{~h}$ at $4^{\circ} \mathrm{C}$. After washing the beads three times with lysis buffer, the proteins captured by the beads were eluted by boiling in the SDS-PAGE sample buffer, resolved by SDS-PAGE, and detected by immunoblotting with anti-GFP antibodies.

Cell imaging. Immunofluorescent samples were observed with an Axiophot microscope equipped with an LSM510 or LSM710 Duo confocal system (Carl Zeiss). For quantification, the pinhole was fully opened and both the gain and offset were fixed. The brightest optical plane was used. Weaker fluorescent samples were observed first to determine conditions; stronger fluorescent samples were then observed. All images of hippocampal neurons were observed at 8-10 DIV and images for all knockdown experiments at $11 \mathrm{DIV}$ (72 $\mathrm{h}$ after transfection). The mean fluorescence intensity and signal density were quantified using Image software, and the images were processed using Photoshop 7.0 (Adobe). When calculating ratios between axonal tip and axon intensities, care was taken not to saturate the signal. The fluorescence profiles of cells were scored using Carl Zeiss LSM image software.

Live imaging. To perform live imaging of GFP-2xFYVE and KIF16BmCherry constructs, 8-10 DIV hippocampal neurons were cotransfected with the indicated constructs. At $12 \mathrm{~h}$ after transfection, live neurons were observed with a Carl Zeiss LSM710 equipped with a $37^{\circ} \mathrm{C}$ incubator. Movement of KIF16B and FYVE was monitored over time, and images were acquired every $2 \mathrm{~s}$. For the determination of the velocities, images were acquired over $100 \mathrm{~s}$. To conduct live imaging of KIF16B, RNAi and control vectors were transfected into 8 DIV hippocampal neurons. After $72 \mathrm{~h}$, live neurons were observed with the Carl Zeiss LSM710 Duo. For rescue experiments, hippocampal neurons were cotransfected with RNAi vector and RNAi-resistant KIF16B for $72 \mathrm{~h}$. The dynamics of FYVE were monitored over time, and images were acquired every $2 \mathrm{~s}$. For KIF16B KD, images were acquired every $10 \mathrm{~s}$ to avoid bleaching the signal from the small endosomes. Velocities were determined over $100 \mathrm{~s}$. To visualize the motility of the EEs in the presence and 

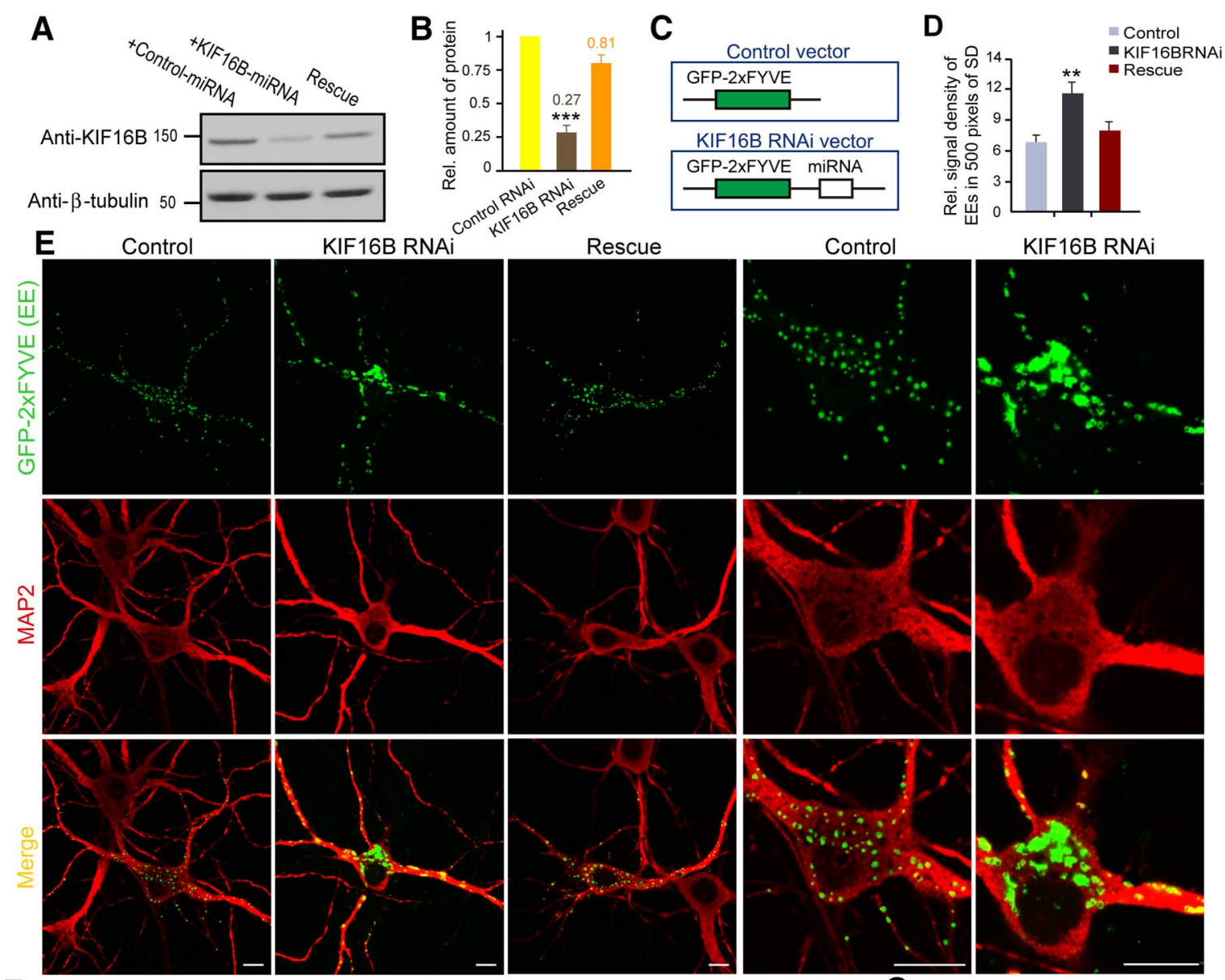

KIF16B RNAi

$F$

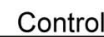

KIF16B RNAi
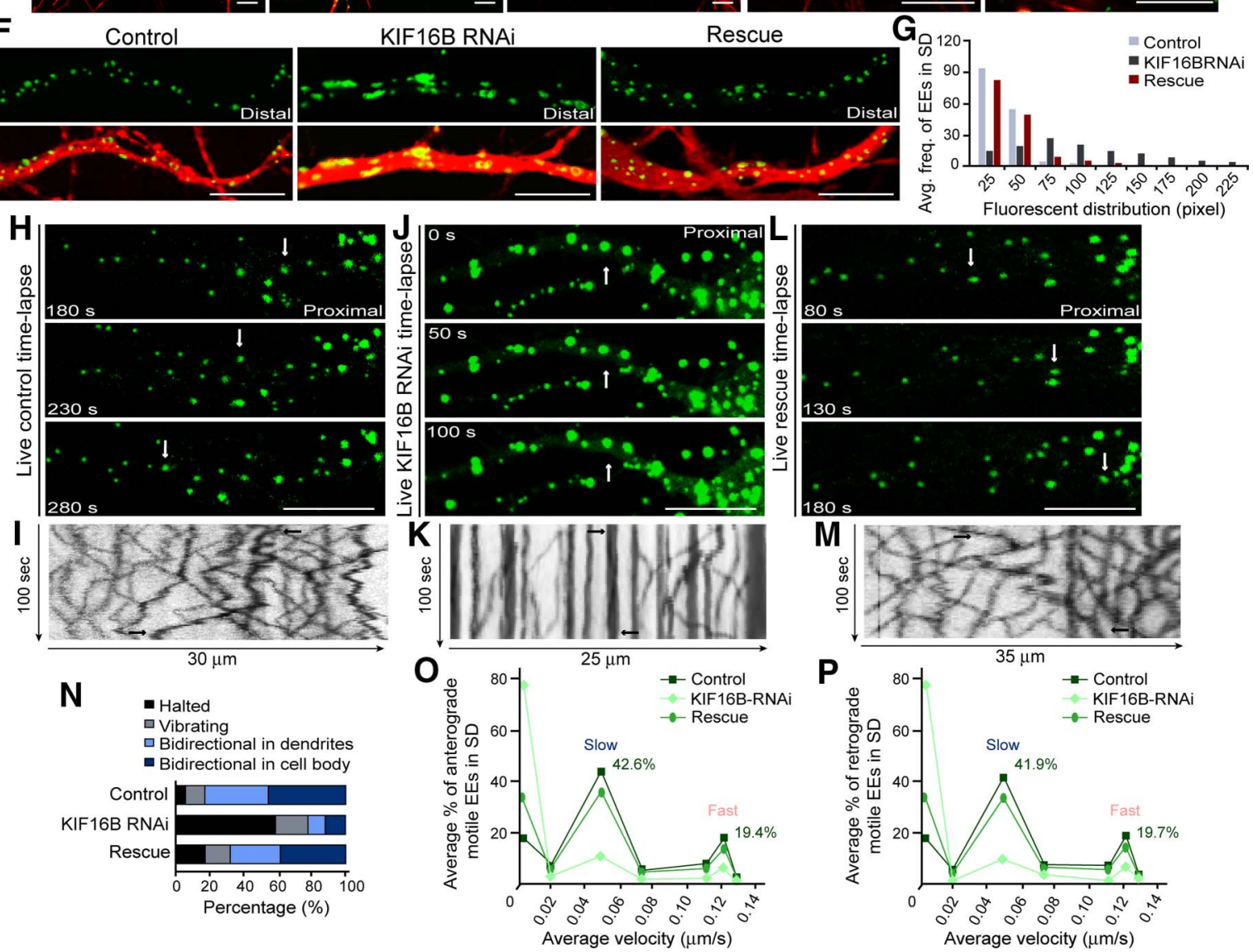

Rescue
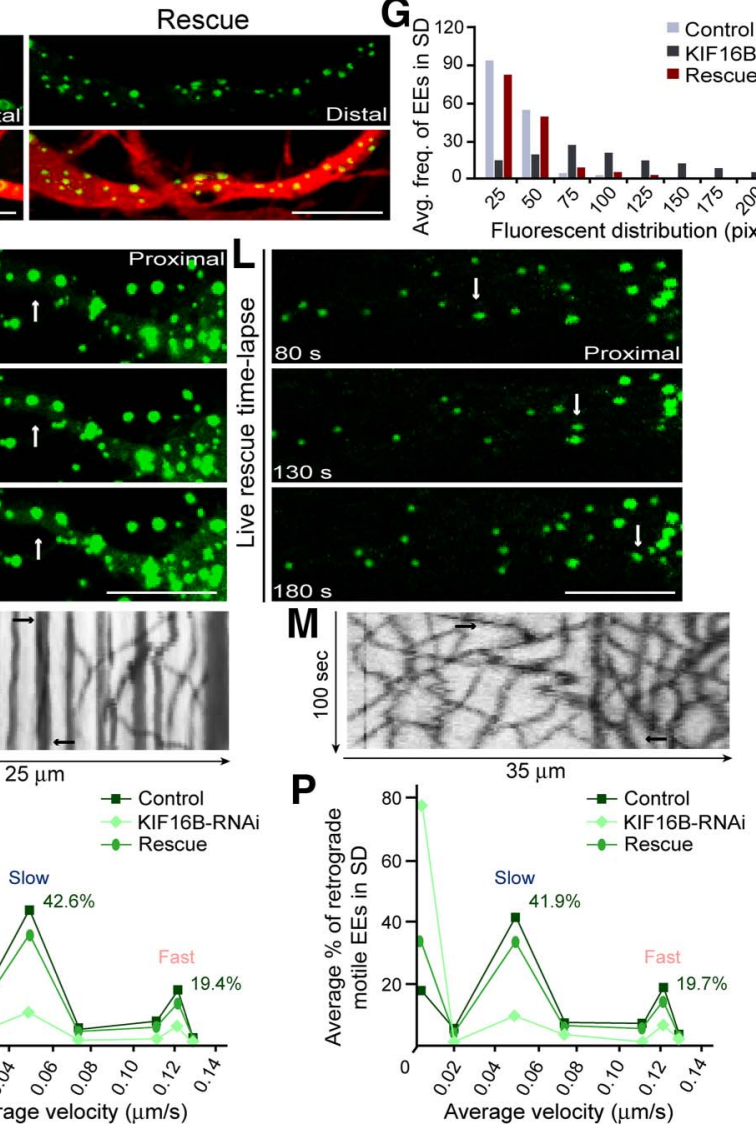

Average velocity $(\mu \mathrm{m} / \mathrm{s})$ 
absence of the inhibitory domain, 8-10 DIV hippocampal neurons were cotransfected with inhibitory domain (ID) + GFP-2xFYVE, whereas control neurons were transfected with only GFP-2xFYVE. After $12 \mathrm{~h}$, the neurons were observed with the Carl Zeiss LSM710 microscope. The movement of FYVE was monitored over time, and images were acquired every $2 \mathrm{~s}$. For ID + FYVE, acquisition was set to every $10 \mathrm{~s}$ to avoid bleaching. Velocities were calculated using images acquired over $100 \mathrm{~s}$. For live imaging, the path of an individual cluster was traced and the distances were evaluated using the LSM710 software. Clusters that vibrated or did not move were not included in velocity quantification. ImageJ software and Photoshop 7.0 (Adobe) were used for analysis and graphical representations.

\section{Results}

\section{KIF16B targets early endosomes to somatodendritic regions of neurons}

In this study, we characterized the functional role of KIF16B in neurons. Previous studies have shown that KIF16B binds to EEs in nonpolarized HeLa cells (Hoepfner et al., 2005; Blatner et al., 2007). Thus, KIF16B is a good candidate motor protein for regulating the somatodendritic localization of EEs in neurons. First, we generated an anti-KIF16B antibody and demonstrated the specificity of this antibody in Western blots of brain, hippocampal neurons (E16), and PC12 cells, as well as in immunocytochemical assays (Fig. 1A,B). Cultured hippocampal neurons were immunostained with the anti-KIF16B antibody and with an anti-EEA1 antibody, a marker for EEs. As a result, endogenous KIF16B was observed to colocalize with the endogenous EEs in somatodendritic regions (Fig. 1A). When human KIF16B-GFP was expressed in neurons, its localization was similar to that of endogenous KIF16B (Fig. 1C,E). Because EEs are not synaptotagminpositive (Hoopmann et al., 2010), we used synaptotagmin as a negative control and found that the KIF16B-GFP signal was distinct from the synaptotagmin punctate labeling (Fig. $1 D, E$ ). Furthermore, the expression of KIF16B-GFP did not change the localization of EEA1-positive EEs, which continued to be localized in the somatodendritic regions. This is consistent with pre-

$\leftarrow$

Figure 3. Knockdown of KIF16B perturbs the movement of early endosomes and causes aggregation. $\boldsymbol{A}, \boldsymbol{B}$, Hippocampal neurons were transfected with control-miRNA, KIF16B-miRNA, or KIF16B-miRNA + KIF16B-RNAi-resistant (rescue) and analyzed with Western blotting. A representative blot is shown, with anti- $\beta$ tubulin serving as a loading control. $B$, Quantification of the relative amount of protein using densitometry normalized to the control-miRNA corresponding to $A$ is shown as mean \pm SD from four independent experiments. Average knockdown: 73\%; average rescue: $81 \%$. ${ }^{* * *} p<0.001$ (Welch's $t$ test). Protein densities were quantified using ImageJ analysis software. $C$, Schematic showing the GFP-2xFYVE insertion used as a transfection and endosomal marker in KIF16B RNAi and control vectors. miRNA was inserted into the $3^{\prime}$-UTR of GFP-2xFYVE CDNA. D-G, Hippocampal neurons were transfected with control-RNAi, KIF16B-RNAi, or KIF16B-RNAi + KIF16B-RNAi-resistant (rescue), and then fixed and stained with an anti-MAP2 antibody (red). D, Relative signal density of EEs in 500 pixels of SD regions normalized to the background density corresponding to $E$. Data are mean \pm SD. ${ }^{* *} p<0.01$ (Student's $t$ test). $\boldsymbol{E}, \boldsymbol{F}$, Localization of the EEs as revealed by GFP-2xFYVE (green) in the cell bodies and along the dendrites. $\mathbf{G}$, Average frequency of EEs in SD regions according to the fluorescent distribution of each cluster, indicating accumulation of EEs in knockdown. $\boldsymbol{H}-\boldsymbol{P}$, Analysis of EE dynamics in control, KIF16B-RNAi, and rescued neurons revealed by GFP2xFYVE (green). $\boldsymbol{H}-\boldsymbol{M}$, Time-lapse images and kymographs. $\boldsymbol{H}, \boldsymbol{I}$, Bidirectional movement of the EEs along a dendrite in a control neuron. Arrows indicate a representative moving $\mathrm{EE} . \boldsymbol{J}, \boldsymbol{K}$, KIF16B RNAi-treated neuron showing many nonmotile and aggregated EEs. Arrows indicate a representative halted EE. $\boldsymbol{L}, \boldsymbol{M}$, Rescued neuron showing recovered bidirectional motility of EEs. Arrows indicate a representative rescued and moving EE. $N$, Classification of movement (control and knockdown: $p<0.001$; control and rescue: $p<0.82 ; \chi^{2}$ test). Average percentage of anterograde $(\boldsymbol{O})$ and retrograde $(\boldsymbol{P})$ motile EEs in somatodendritic regions based on average velocity. Vibrating clusters were not counted. No significant difference between $\boldsymbol{O}$ and $\boldsymbol{P}$ (oneway ANOVA and post hoc test). Eighteen neurons from three independent experiments were analyzed. Scale bars, $10 \mu \mathrm{m}$. vious studies showing that KIF16B-GFP accurately reflects the localization of endogenous KIF16B (Hoepfner et al., 2005; Blatner et al., 2007). Thus, we took advantage of this probe to observe the precise intracellular localization of KIF16B in cells using immunofluorescence microscopy.

Several types of neuronal KIFs have been reported: axonspecific KIFs, dendrite-specific KIFs, and ubiquitous KIFs (Setou et al., 2000; Nakata and Hirokawa, 2003; Jacobson et al., 2006; Huang and Banker, 2012). To clarify the localization of KIF16B in neurons, KIF16B-GFP-expressing cells were stained with the dendritic marker MAP2 and a neuronal marker, anti- $\beta 3$ tubulin. GFP-expressing neurons were used as control (Fig. 1F). KIF16BGFP was significantly localized in the somatodendritic regions of hippocampal neurons, but not in the axons (Fig. 1G,H). EEA1positive EEs were also specifically localized in the cell body and dendrites, as shown in Figure $1 A, C$. These results indicate that both KIF16B and EEA1-positive EEs are specifically localized to the somatodendritic region of neurons.

Previous studies have used tandemly chained FYVE domains fused with GFP (GFP-2xFYVE) as an EE marker because the FYVE domain is the C-terminal part of EEA1 protein that specifically binds to the PI3P of EEs and does not affect their localization or function (Burd and Emr, 1998; Komada and Soriano, 1999; Ellson et al., 2001). Therefore, 2xFYVE generated from an HGF-regulated tyrosine kinase substrate and fused with GFP served as an EE marker. The somatodendritic localization of GFP-2xFYVE is almost identical to that of endogenous EEs, as revealed by the anti-EEAl antibody, validating its use as an EE marker in neurons (data not shown) (Wilson et al., 2000). We conducted dual-color live imaging of hippocampal neurons cotransfected with GFP-2xFYVE and KIF16B-mCherry to evaluate the movement and colocalization of KIF16B and EEs in neurons. Time-lapse recordings, kymographs, and quantification revealed bidirectional movement of KIF16B colocalized with EEs in the cell bodies and dendrites (Fig. 1I-M; Movie 1). This bidirectional motion is consistent with the bidirectional polarity of microtubules (MTs) in somatodendritic regions. The distribution and dynamics were similar to those of endosomes in nonneuronal cells, exhibiting a distinctive intracellular localization and both short- and long-range movements with a range of velocities (Nielsen et al., 1999; Gasman et al., 2003; Hoepfner et al., 2005). Analysis of vesicle velocities revealed biphasic slow and fast distributions, with no significant difference in anterograde and retrograde directions $(0.048$ and $0.121 \mu \mathrm{m} / \mathrm{s}$, respectively; Fig. $1 N$ ). The range of KIF16B velocities may be impacted by the cargoes carried in the EEs and/or by associated proteins. A previous study showed that the expression of RhoD and hDia2C reduces and regulates the motility of EEs through interactions with the cytoskeleton in HeLa cells (Gasman et al., 2003). Collectively, our immunocytochemistry and live imaging results demonstrate that KIF16B comigrates with EEs in the somatodendritic regions of neurons.

\section{The C terminus of KIF16B is the early endosomal binding domain}

To clarify the functional details of the KIF16B molecular motor protein in neurons, we sought to identify the EE binding domain. We constructed KIF16B mutants and expressed them in neurons (Fig. 2A). The KIF16B PX-only mutant (KIF16BPX-GFP; Fig. $2 A$ ) displayed a somatodendritic endosomal distribution pattern that colocalized with endogenous EEs, similar to full-length KIF16B (KIF16BFull-GFP), indicating that the $\mathrm{C}$ terminus is sufficient for EE association (Fig. $2 B-D$ ). In an alternatively spliced 


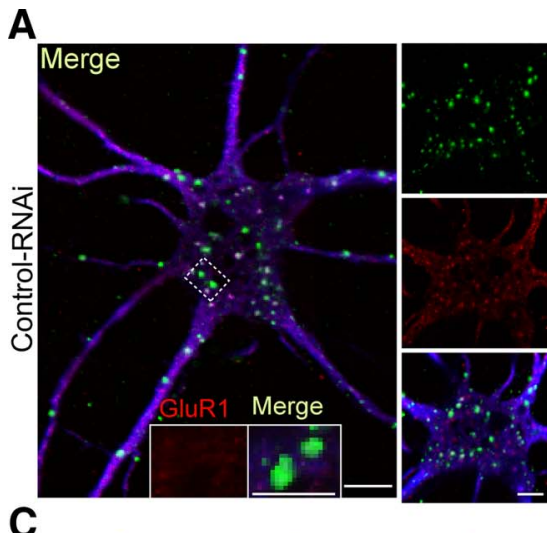

B Control-RNAi
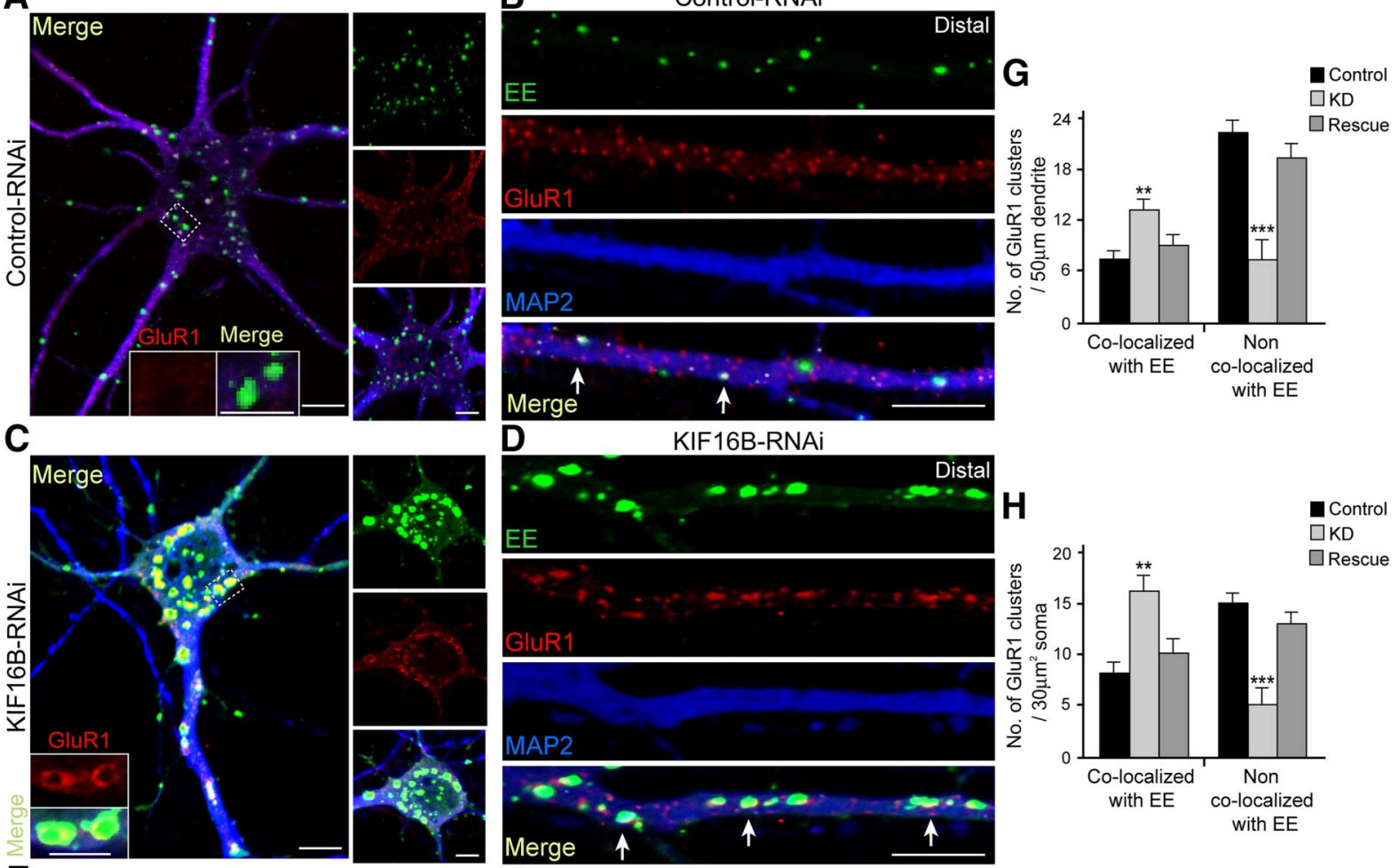

E
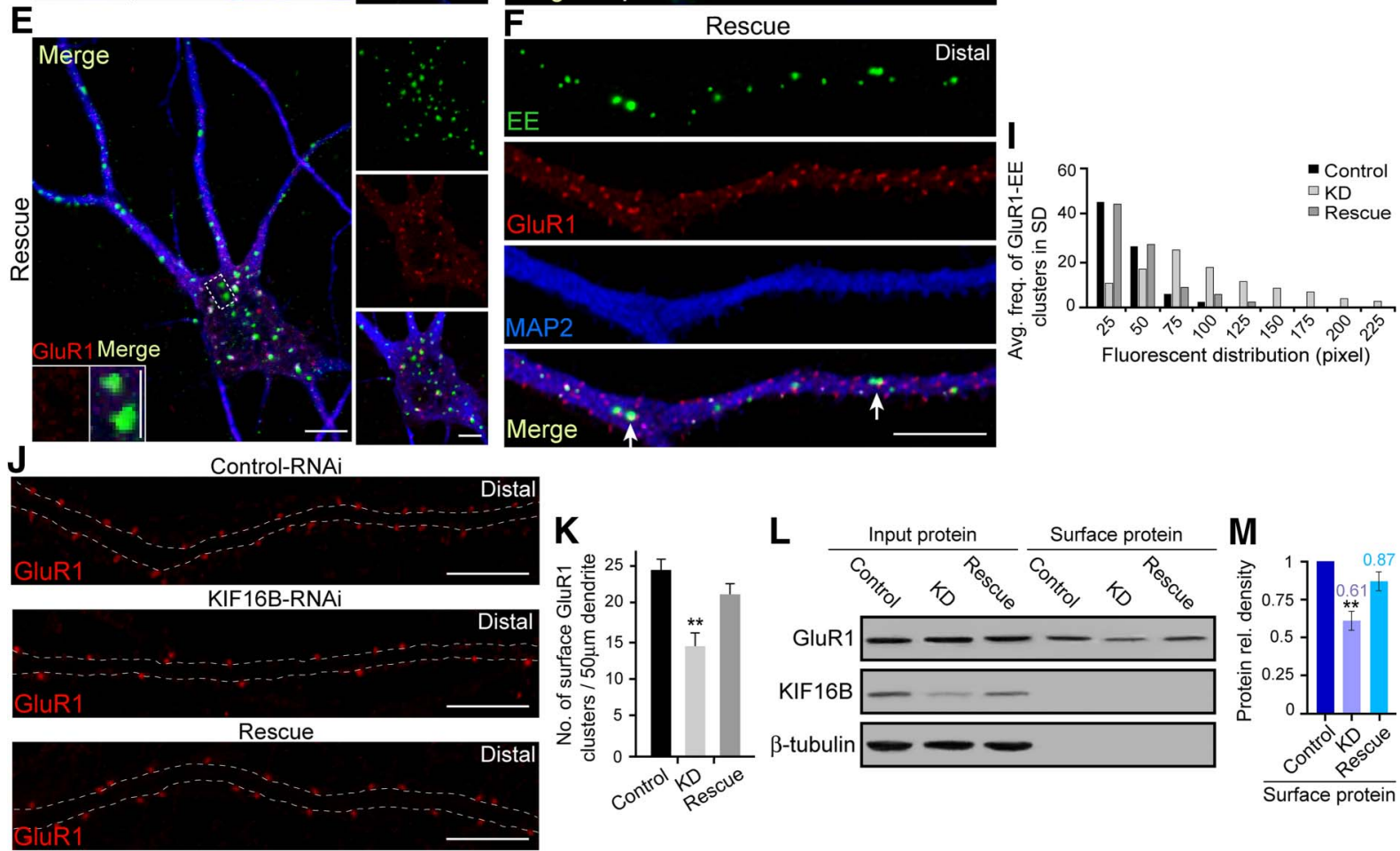

$\mathrm{N}_{\text {CT }}$

KD

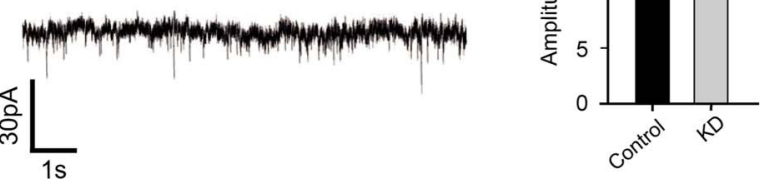

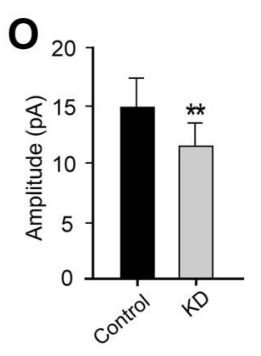

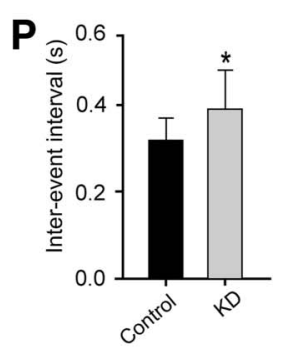

Q

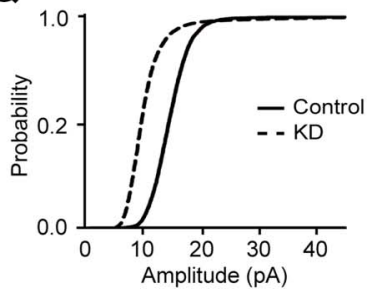


variant of KIF16B that was distinct from the one we used, L1248/ F1249 point mutations in the PX domain abrogate the binding of KIF16B to EEs in HeLa cells (Blatner et al., 2007). Hence, for further analysis, we introduced similar L1197A/F1198A point mutations in the human PX domain to generate a mutant construct, KIF16BPXmut-GFP. When this protein was expressed in hippocampal neurons, the fluorescence signal of KIF16BPXmutGFP was diffuse, and EEs clustered in the cell body and dendrites, in contrast to the even endosomal distribution pattern of fulllength KIF16B or the PX domain (Fig. 2E,F). Identical to the localization of the GFP control, KIF16BPXmut-GFP was distributed throughout the neuronal cytosol and did not display an endosomal localization pattern (Fig. 2E, G-J). Collectively, these data indicate that the PX domain of the C-terminal of KIF16B is required for its association with EEs and that L1197 and F1198 residues are critical for attachment.

\section{Knockdown of KIF16B perturbs the movement of early endosomes}

Next, to determine the impact of KIF16B in neurons, knockdown was performed using RNAi, and the localization of EEs was observed. KIF16B knockdown efficiency assessed with Western blot analysis showed that RNAi significantly inhibited the expression of KIF16B. Moreover, this knockdown could be rescued by RNAi-resistant KIF16B (average knockdown: 73\%; average rescue: $81 \%$; Fig. $3 A, B$ ). To serve as a transfection control and an EE marker during knockdown, GFP-2xFYVE was cloned into the target miRNA vector (Fig. $3 C$ ), with similar expression condi-

\section{$\leftarrow$}

Figure 4. Loss of KIF16B results in altered GluR1 and AMPA receptor trafficking. $A-I$, Neurons expressing RNAi were permeabilized and costained with anti-GluR1 (red) and anti-MAP2 (blue) antibodies. Localization of EEs revealed by the EE marker, GFP-2xFYVE (green). $\boldsymbol{A}, \boldsymbol{B}$, Representative neuron transfected with the control miRNA vector. Insets (magnified), Example of noncolocalized GluR1 with EEs in the cell body. $\boldsymbol{B}$, Lower density of colocalized GluR1 with EEs along the dendrite. $\boldsymbol{C}, \boldsymbol{D}$, Representative neuron transfected with KIF16B miRNA (KD). Enlargements represent an example of aggregated and colocalized GluR1s with EEs in the soma. $\boldsymbol{D}$, Aggregation and an increased number of colocalized GluR1-EEs along the KD dendrite. $\boldsymbol{E}, \boldsymbol{F}, \mathrm{A}$ representative neuron cotransfected with the KIF16B miRNA + KIF16B-RNAi-resistant (rescue). Insets (magnified), Example of noncolocalized GluR1 with EEs in the cell body. F, Aggregation and a high density of colocalized GluR1s with EEs were inhibited along the dendrite by the KIF16B-RNAi-resistant construct. Somas are shown separately for EEs, GluR1s, and the merged image in the $\boldsymbol{A}, \boldsymbol{C}, \boldsymbol{E}$ (right side). $\boldsymbol{B}, \boldsymbol{D}, \boldsymbol{F}$, Arrows indicate representative examples of colocalized GluR1s and EEs. $\mathbf{G}, \boldsymbol{H}$, Quantifications of the total number of GluR1 clusters colocalized and not colocalized with EEs: per $50 \mu \mathrm{m}$ of dendrites $(\boldsymbol{G})$ and per $30 \mu \mathrm{m}^{2}$ of soma $(\boldsymbol{H})$. $\boldsymbol{I}$, Average frequency of GluR1-EE clusters in SD region according to the fluorescent distribution of each cluster, showing accumulation of EEs in KD neurons. $\boldsymbol{J}, \boldsymbol{K}$, Neurons expressing the miRNA were stained with anti-GluR1 antibody without permeabilization to visualize the cell surface clusters. J, Representative images of dendrites expressing the control, RNAi vector, and rescue constructs show a reduced number of surface clusters in $K D$ and a recovery in rescued neurons. White dotted outlines indicate the dendritic membranes. $\boldsymbol{K}$, Statistical analysis of the number of surface GluR1 clusters per $50 \mu \mathrm{m}$ of dendrites. Images were analyzed with ImageJ software. Scale bars, $10 \mu \mathrm{m}$. $\boldsymbol{L}, \boldsymbol{M}$, Cell surface protein biotinylation analysis. $\boldsymbol{L}$, Cell surface evaluation of proteins in KIF16B-RNAi, control, and rescue hippocampal neurons. $M$, Quantification of protein relative density using densitometry normalized to the control. The absence of intracellular $\beta$-tubulin verified the purity of the cell surface protein fraction. Anti-KIF16B was used as knockdown efficiency control. Protein densities were quantified using ImageJ software. $\mathbf{N}-\mathbf{Q}$, Electrophysiological analysis of AMPA receptors. $N$, Representative traces showing mEPSC recorded from cultured hippocampal neurons of control-and KD-transfected cells. 0, Amplitude of AMPA receptor-mediated $\mathrm{mEPSCs}$ (control: $14.7 \pm 2.6 \mathrm{pA}$; KD: $11.5 \pm 2.4 \mathrm{pA}$ ). $\boldsymbol{P}$, Interevent interval of AMPA receptor-mediated mEPSCs (control: $0.32 \pm 0.06 ; \mathrm{KD}: 0.39 \pm 0.09$ ). Q, Cumulative probability curves for amplitude of AMPA receptor-mediated $\mathrm{mEPSCs}$. For all statistical analyses, error bars indicate mean \pm SD. Fifteen neurons for each vector from three independent transfections were examined. ${ }^{*} p<0.05$ (Student's $t$ test). ${ }^{* *} p<0.01$ (Student's $t$ test). ${ }^{* * *} p<0.001$ (Student's $t$ test). $\boldsymbol{M}, n=3$ independent experiments; Welch's $t$ test. tions for control, RNAi, and RNAi-resistant transfected neurons. In control hippocampal neurons, EEs were uniformly distributed in the somatodendritic regions (Fig. 3D-G). When KIF16B was knocked down, EEs formed aggregates both in the cell body and dendrites (Fig. 3D-G). In rescue experiments, cotransfection of RNAi-resistant KIF16B with the KIF16B RNAi vector largely prevented the aggregation of EEs (Fig. 3D-G). To confirm the immunostaining results in KIF16B RNAi-treated and control cells, we conducted time-lapse imaging. Time-lapse images and kymographs revealed that the bidirectional motility of the EEs was perturbed in KIF16B knockdown neurons compared with that in controls (Fig. $3 H-K$ ). In the KIF16B knockdown neurons, the average number of motile EEs was markedly decreased and the labeled endosomes aggregated and were immobilized compared with those in controls (Fig. $3 N$ ). The EE aggregation phenotype in KIF16B knockdown neurons was consistent with results in fungus (Ustilago maydis) showing that a kinesin-3 null mutation results in immobile clusters of EEs in hyphal cells (Bielska et al., 2014). Coexpression of RNAi-resistant KIF16B with the KIF16B RNAi vector restored the motility of EEs (Fig. $3 L-N)$ ). The distribution of the velocities was bimodal, with a slow and fast peak in control, KIF16B knockdown, and rescued neurons (Fig. 3O,P). The effect of KIF16B knockdown on EE movement was not significantly different between anterograde and retrograde directions. The percentage of motile EEs was as follows: control, $83 \%$; knockdown, 22\%; rescue, $68 \%$ (Fig. $3 N-P$ ). Together, these results suggest that KIF16B is essential for EE transport in somatodendritic regions of neurons.

\section{KIF16B modulates receptor trafficking}

Because it is well known that EEs participate in receptor trafficking, we studied the effects of KIF16B knockdown on cellular localization of receptors. We examined the distribution of glutamate receptor 1 (GluR1), a subunit of the AMPA receptor, in control and KIF16B knockdown neurons. The results of the immunocytochemical assays showed that the number of GluR1 clusters colocalized with EEs was increased, whereas the number of GluR1 clusters not colocalized with EEs was decreased, in KIF16B knockdown neurons compared with those in control (Fig. $4 A-D, G, H$ ). These EE-GluR1 clusters aggregated in dendrites and the perinuclear region of the cell body (Fig. 4C,D,I). These effects of KIF16B knockdown on GluR1 were largely avoided when the KIF16B miRNA vector was cotransfected with the KIF16B miRNA-resistant construct (Fig. 4E-I). Because these results suggested an alteration in the trafficking of GluR1, we compared the surface expression of GluR1 in control and KIF16B knockdown neurons. Immunofluorescence staining of cell surface GluR1 revealed that the number of GluR1 receptors on the cell surface was significantly reduced in KIF16B knockdown neurons (Fig. $4 \mathrm{~J}, \mathrm{~K}$ ). This result was confirmed using surface biotinylation, which showed that cell surface expression of GluR1 in KIF16B knockdown neurons was significantly reduced compared with that in controls (Fig. $4 L, M$ ). Cotransfection of the KIF16B RNAi-resistant construct rescued the defect in cell surface GluR1 expression induced by KIF16B RNAi (Fig. 4J-M).

To investigate the physiological impact of the mislocalization of the AMPA receptor, we performed whole-cell patch-clamp recordings of cultured hippocampal neurons. KIF16B knockdown or the control vector was transfected into neurons and mEPSCs were recorded. We observed a reduction in mean amplitude and an increase in mean interevent interval of AMPA receptor-mediated mEPSCs in neurons transfected with the knockdown construct compared with those transfected with the 

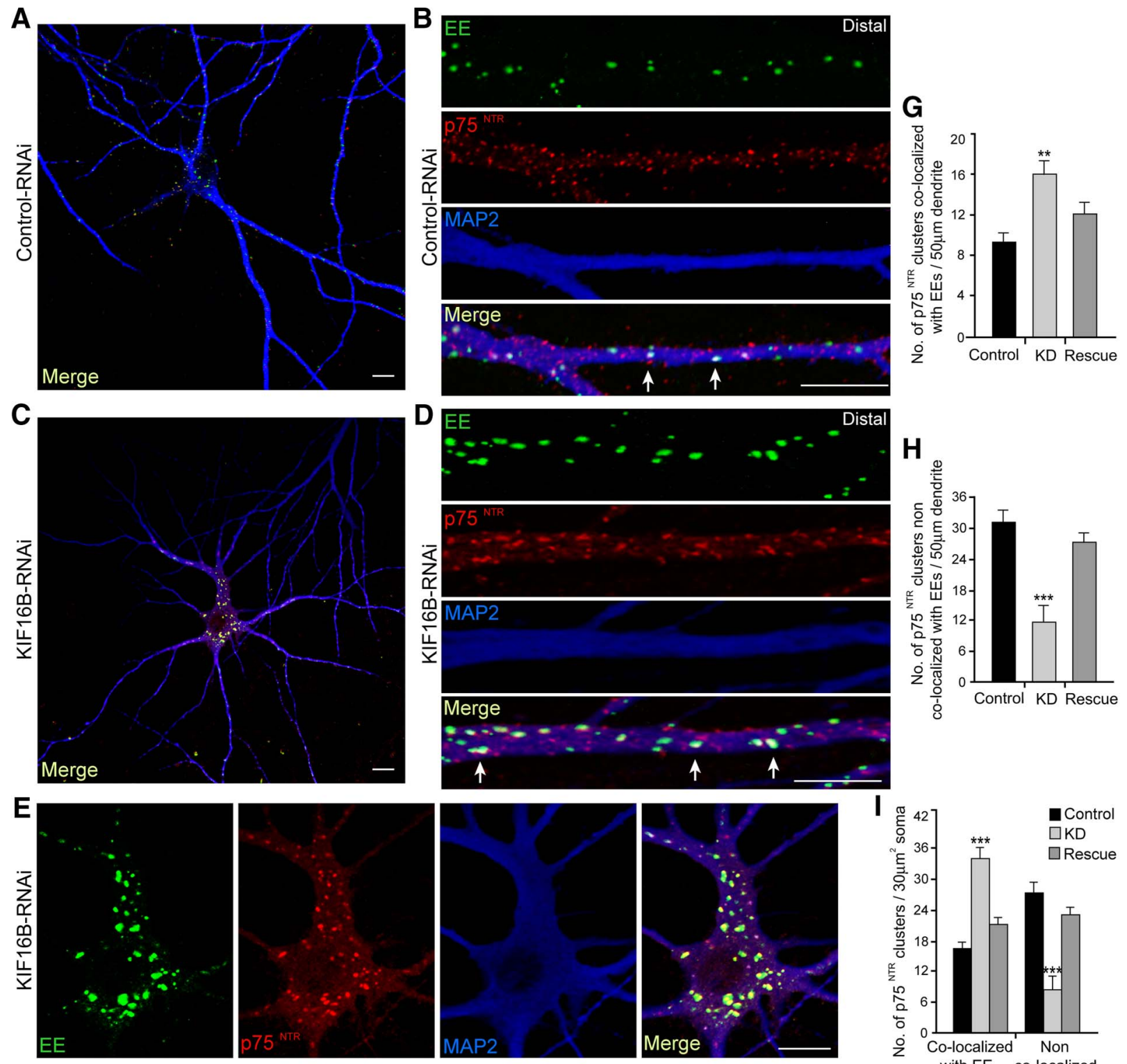

$\frac{6}{\frac{6}{\Sigma}}$
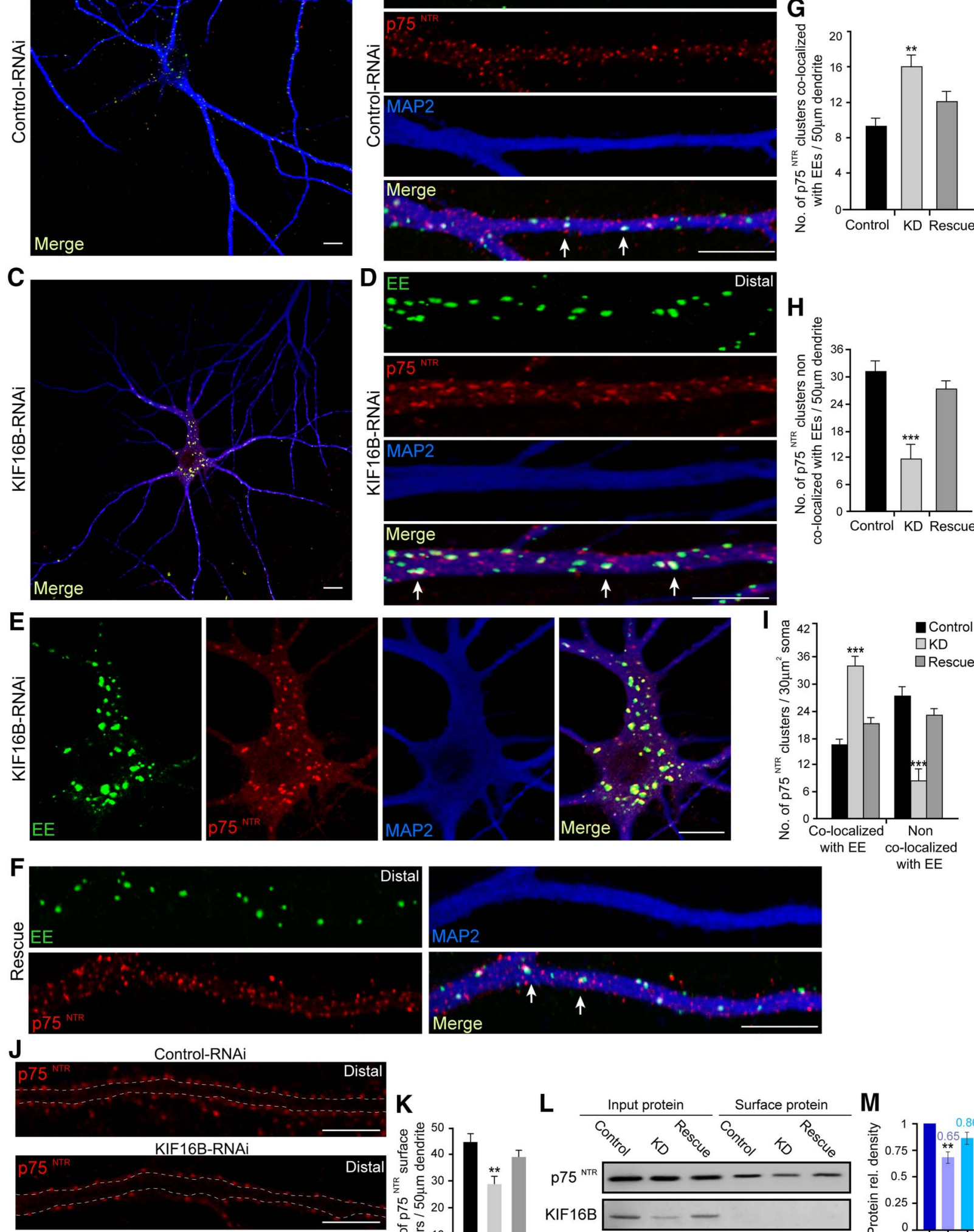

$\mathbf{L} \quad$ Input protein Surface protein $\mathbf{M}$

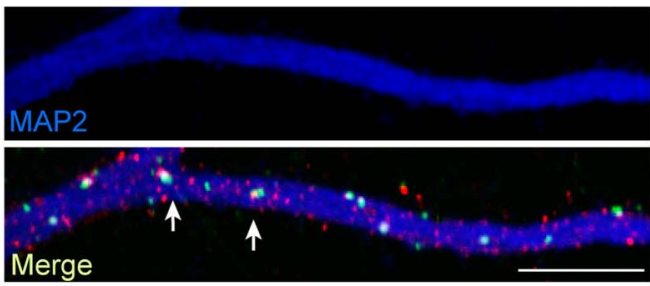
with $\mathrm{EE}$

Rescue

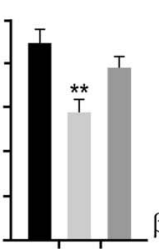

KIF16B
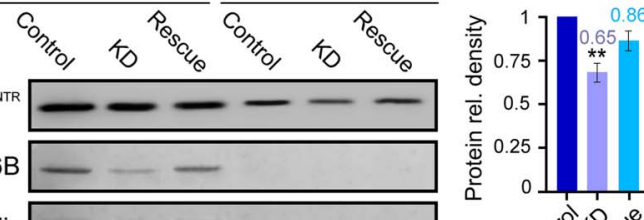

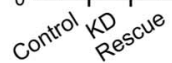

$\beta$-tubulin $\longrightarrow$ 
control vector (amplitude: control, $14.7 \pm 2.6 \mathrm{pA}$; knockdown, $11.5 \pm 2.4 \mathrm{pA}$ ) (interevent interval: control, $0.32 \pm 0.06 \mathrm{~s}$; knockdown, $0.39 \pm 0.09 \mathrm{~s}$ ) (Fig. $4 \mathrm{~N}-\mathrm{P}$ ). A cumulative probability curve also indicated a leftward shift toward smaller amplitudes in KIF16B knockdown neurons (Fig. 4Q). These data indicate a decrease in AMPA receptor function in KIF16B knockdown neurons.

To confirm the role of KIF16B in receptor trafficking, we also examined the localization of another type of receptor, p75 ${ }^{\text {NTR }}$ (a low-affinity nerve growth factor receptor) (Woo et al., 2005), in control and KIF16B knockdown neurons. Immunocytochemistry showed that the number of $\mathrm{p} 75^{\mathrm{NTR}}$ clusters colocalized with EEs was increased, whereas the density of $\mathrm{p} 75^{\mathrm{NTR}}$ clusters not colocalized with EEs was decreased, in KIF16B knockdown neurons (Fig. $5 A-E, G-I$ ). These $75^{\mathrm{NTR}}$ clusters colocalized with the EEs and appeared to aggregate in the dendrites and the perinuclear region of the cell body (Fig. $5 C-E, G-I$ ). This defect in p75 ${ }^{\text {NTR }}$ localization induced by KIF16B RNAi was rescued by coexpression of RNAi-resistant KIF16B (Fig. 5F-I).

Next, we compared the surface expression of $\mathrm{p} 75^{\mathrm{NTR}}$ in control and KIF16B knockdown neurons. Immunofluorescence staining of cell surface $\mathrm{p} 75^{\mathrm{NTR}}$ revealed that the cell surface density of the receptor was significantly reduced in KIF16B knockdown neurons (Fig. $5 G, K$ ). Surface biotinylation also showed that cell surface expression of $\mathrm{p} 75^{\mathrm{NTR}}$ was significantly reduced in KIF16B knockdown neurons compared with that in controls (Fig. $5 L, M$ ). This reduction in surface density was largely prevented when the KIF16B RNAi-resistant construct was cotransfected with the miRNA vector (Fig. 5J-M). Together, these findings suggest that the loss of KIF16B results in altered receptor trafficking in neurons.

\section{The second and third coiled-coils of the stalk domain are critical for the proper localization of KIF16B and early endosomes}

To identify the KIF16B domain responsible for the localization of EEs in somatodendritic areas, we generated various mutant con-

\footnotetext{
$\leftarrow$

Figure 5. Loss of KIF16B alters the trafficking of p75 NTR (NGFR). $\boldsymbol{A}-\boldsymbol{I}$, miRNA and control vectors were transfected into neurons, which were permeabilized and double-stained with anti-p75 NTR (low-affinity nerve growth factor receptor) (red) and anti-MAP2 (blue) antibodies. Localization of EEs revealed by the EE marker, GFP-2xFYVE (green). $A, B$, Representative neuron transfected with control miRNA shows fewer colocalized $\mathrm{p} 75^{\mathrm{NTR}}$-EEs along the dendrite. $\boldsymbol{C}-\boldsymbol{E}$, Representative neuron transfected with KIF16B miRNA vector (KD). D, E, Accumulation and increased colocalization of $\mathrm{p} 75^{\mathrm{NTR}}$ with EE clusters: along a dendrite $(\boldsymbol{D})$ and in the perinuclear region of the cell body of a $K D$ neuron $(\boldsymbol{E})$. $\boldsymbol{F}$, Image of a representative dendrite cotransfected with the KIF16B miRNA + KIF16B-RNAi-resistant (rescue) constructs shows rescue in the density of colocalized p $75^{\text {NTR }}$-EEs along the dendrite. G-I, Quantifications of the total number of p75 ${ }^{\text {NTR }}$ clusters colocalized and not colocalized with EEs: per $50 \mu \mathrm{m}$ of dendrites $(\boldsymbol{G}, \boldsymbol{H})$ and per $30 \mu \mathrm{m}^{2}$ of soma $(\boldsymbol{I}) . \boldsymbol{J}, \boldsymbol{K}$, Neurons expressing the RNAi vectors were stained with anti-p $75^{\text {NTR }}$ (red) antibody without permeabilization to visualize the cell surface clusters. $J$, Representative dendrites expressing the control, RNAi vector, and rescue show a reduced number of surface p75 ${ }^{\text {NTR }}$ clusters in KD and a recovery in rescued neurons. White dotted outlines indicate the dendritic membranes. $\boldsymbol{K}$, Statistical analysis of the number of surface $\mathrm{p} 75^{\mathrm{NTR}}$ clusters per $50 \mu \mathrm{m}$ of dendrites. Quantifications were performed with ImageJ software. Scale bars, $10 \mu \mathrm{m} . \boldsymbol{L}, \boldsymbol{M}$, Cell surface protein biotinylation analysis. $L$, Cell surface evaluation of proteins in KIF16B-RNAi, control, and rescue hippocampal neurons. $\boldsymbol{M}$, Quantification of protein relative density using densitometry normalized to the control. The absence of intracellular $\beta$-tubulin verified the purity of the cell surface protein fraction. Anti-KIF16B was used as knockdown efficiency control. Protein densities were quantified using ImageJ software. For all quantifications, error bars indicate mean \pm SD. Fifteen neurons for each vector from three independent transfections were analyzed; Student's $t$ test. $\boldsymbol{M}$, Data are from three independent experiments. ${ }^{* *} p<0.01$ (Welch's $t$ test). ${ }^{* * *} p<0.001$ (Welch's $t$ test).
}

structs and expressed them in neurons. Interestingly, when the third coiled-coil of KIF16B was deleted (KIF16B936-GFP), the protein accumulated in some neurites. MAP2 and tubulin- $\beta 3$ staining revealed that KIF16B936-GFP specifically accumulated in the tips of axons (Fig. $6 A, B, E$ ). Thus, we set out to identify the region critical for the mislocalization of KIF16B. We made several mutants; and among them, only the KIF16B810-GFP mutant lacking the second and third coiled-coils displayed a localization similar to that for KIF16B936-GFP, localized to the tips of axons (Fig. 6C-E). Neurons expressing KIF16BFull and GFP were used as controls for somatodendritic endosomal and diffuse patterns, respectively (statistics are presented; images of controls are not displayed in Fig. 6 as they are shown in Figs. 1, 2, and 3). These results suggest that the second and third coiled-coil domains of KIF16B are important for the localization of KIF16B; in their absence, KIF16B accumulates in the tips of axons.

To clarify whether the mislocalization of KIF16B in axonal tips would be affected by binding to EEs, we generated a construct that lacked the second and third coiled-coil domains but retained the PX domain (KIF16B810-PX-GFP; Fig. 6A). This protein also moved along axonal shafts and accumulated in axonal tips (Fig. $6 F, H)$. Using a constitutively active KIF5C motor domain and the PX domain of KIF16B, we generated a chimera to determine whether the motor domain had any effect on the localization of KIF16B. Interestingly, we observed that the chimeric protein also moved along axonal shafts and accumulated in their tips (Fig. $6 G, H)$. Analysis of the axon per dendrite signal intensity as well as the axonal density of mutant proteins per axonal density of GFP control revealed significant differences between controls (KIF16BFull and GFP), KIF16B810-PX, and chimera mutants (Fig. 6I,J). These results demonstrate that the second and third coiled-coil domains of KIF16B are crucial for the somatodendritic localization of KIF16B.

Previous studies have shown that cargo localization is regulated by the association and dissociation with motor proteins (Glater et al., 2006; Guillaud et al., 2008; Niwa et al., 2008). If the association and dissociation between KIF16B and EEs determine the somatodendritic localization of EEs, then KIF16B810-PX, which mislocalizes to axons, should not alter the somatodendritic localization of EEs. To test this hypothesis, we investigated the localization of EEs in neurons expressing KIF16B810-PX. Whereas in controls KIF16BFull and EEs were specifically localized to somatodendritic regions (Fig. 7A,B), KIF16B810-PX drove endosomes to the tips of axons (Fig. $7 A, C, D$ ). Contrary to our hypothesis, the EEs were missorted to the axonal tips in neurons expressing KIF16B810-PX (Fig. 7C,D). The mislocalized endosomes colocalized with KIF16B810-PX (Fig. 7C-E), suggesting that the recombinant motor protein directly transported EEs into the axons. Together, these data suggest that the second and third coiled-coils of the KIF16B stalk domain are pivotal in determining not only the localization of KIF16B itself, but also the somatodendritic localization of EEs in neurons.

\section{The second and third coiled-coil domains of KIF16B work as an inhibitory domain}

The preceding results suggest that the second and third coiledcoils of the KIF16B stalk domain affect the localization of KIF16B. Because the localization of KIF16B810 is similar to that of constitutively active KIF5, we hypothesized that KIF16B810 might be overactive (Jacobson et al., 2006). To clarify how the second and third coiled-coils control the localization of KIF16B and EEs, we conducted biochemical assays. First, we conducted a microtubule cosedimentation assay to examine the binding of the mutant 


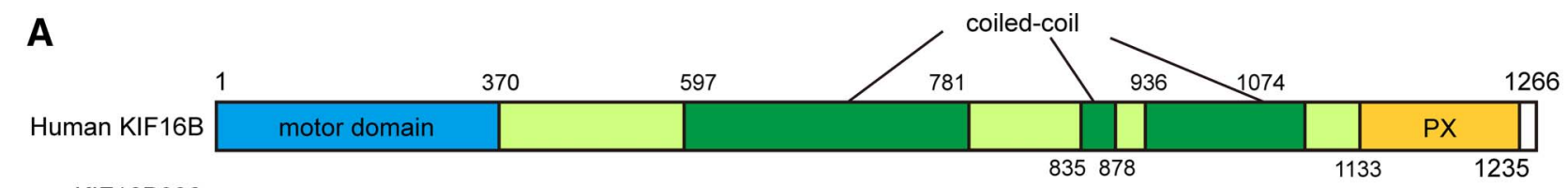

KIF16B936

KIF16B810

KIF16B810-PX

Chimera

B

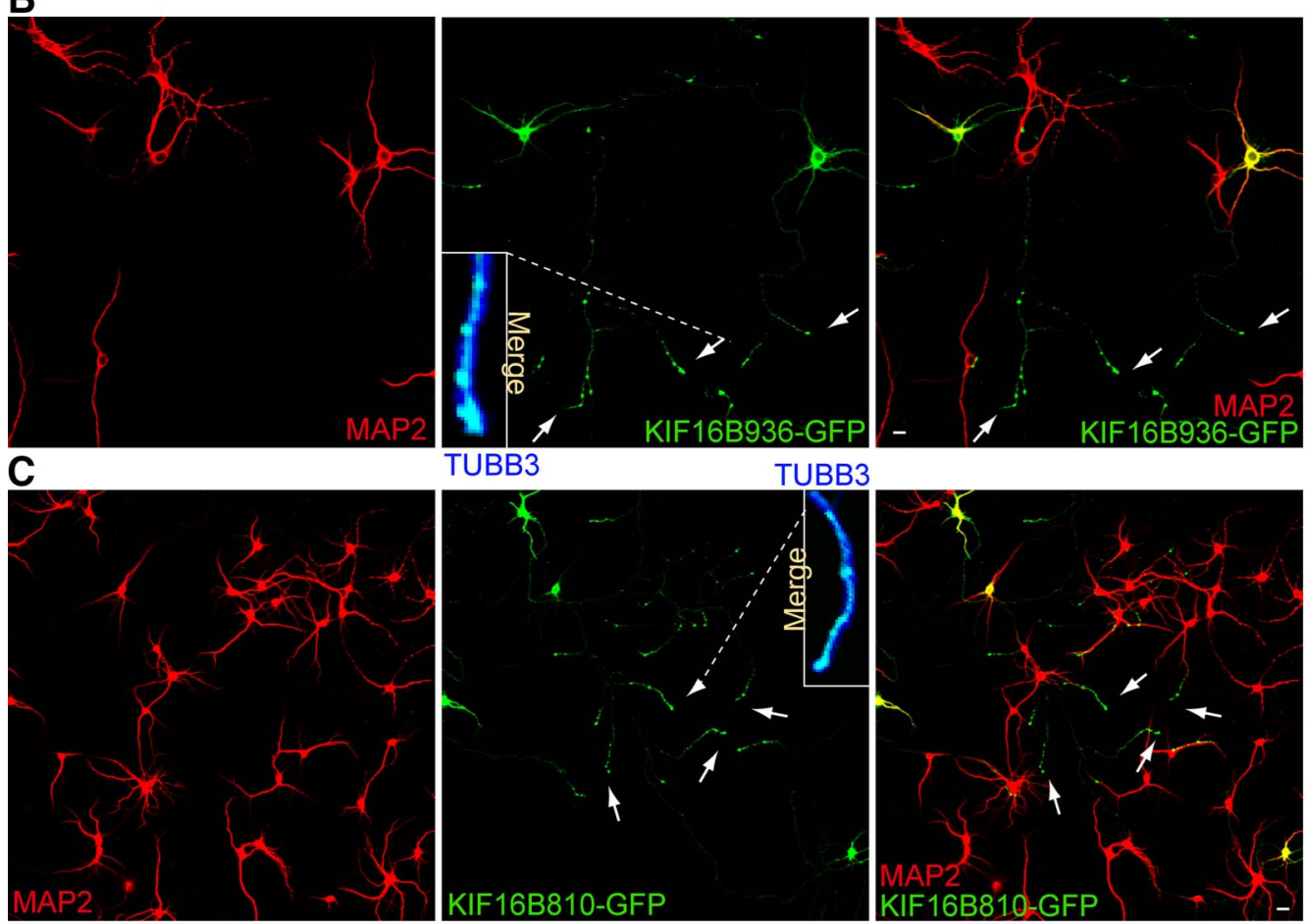

KIF5C

KIF16B
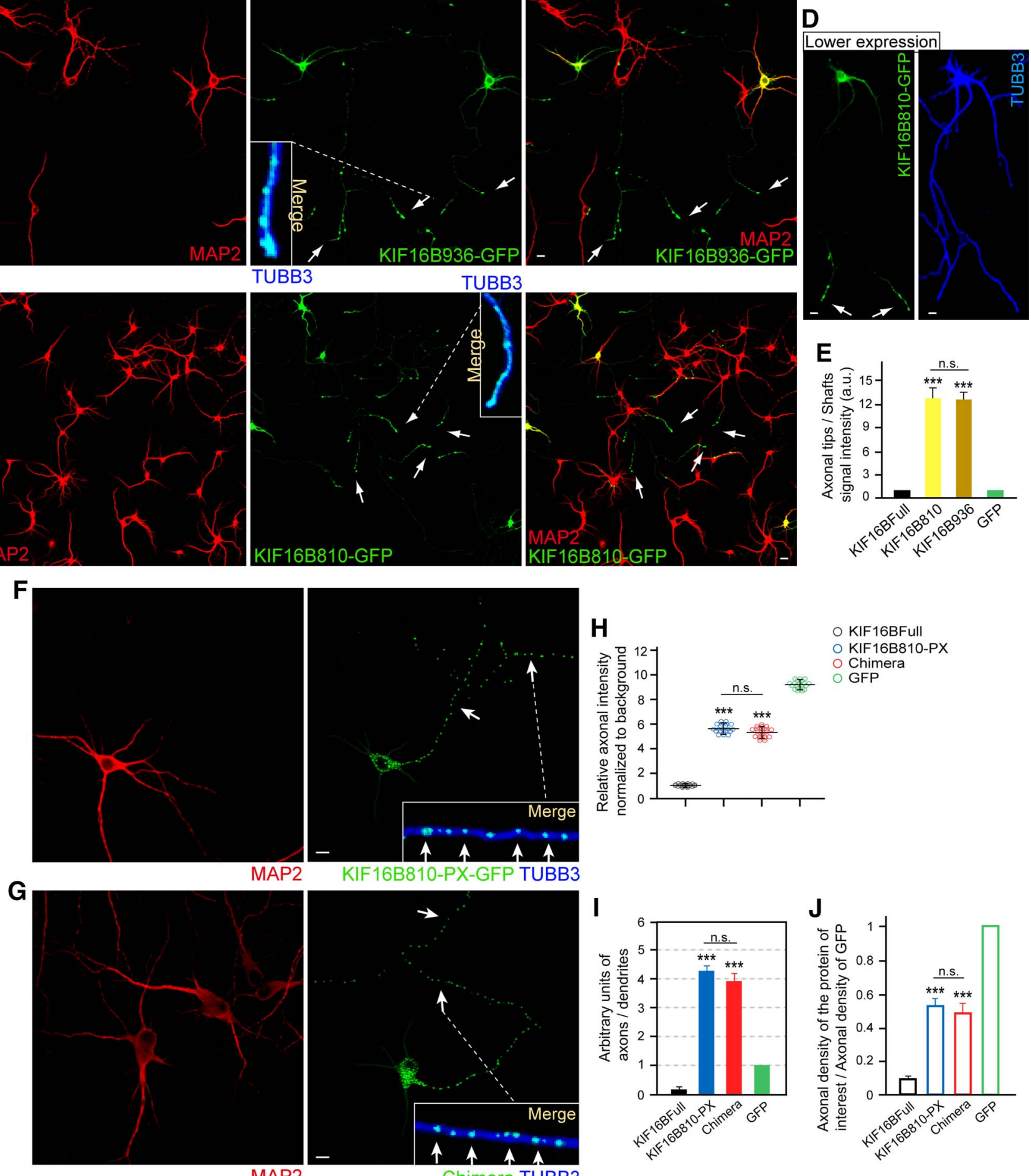
KIF16B proteins to MTs in COS-7 cells. Free MTs, polymerized from brain tubulin, were added to the lysed cells. Then, the MTs were sedimented by ultracentrifugation. Initially, KIF16B810 and KIF16B1096 were tested because the former lacks the second and third coiled-coils and accumulates in axonal tips, whereas the latter contains the second and third coiled-coils but does not accumulate in any region and was diffusely distributed throughout the neuron (Fig. 8A,B). Approximately half of the KIF16B810 sedimented with the MTs, and the remaining protein was cytosolic (Fig. 8C-E). However, KIF16B1096, which possesses the second and third coiled-coils, did not cosediment with the MTs and was maintained in the cytoplasmic fraction (Fig. $8 C$ ). Importantly, in the presence of AMP-PNP, which is a nonhydrolyzable analog of ATP and a competitive inhibitor of ATP-dependent enzyme systems, a considerable amount of KIF16B1096 cosedimented with MTs (Fig. 8D,E). The construct that lacked the second and third coiled-coils but contained the PX domain (KIF16B810-PX) showed almost the same level of MT binding as KIF16B810. Furthermore, neither KIF16B810 nor KIF16B810-PX showed a significant difference in binding to MTs in the presence or absence of AMP-PNP (Fig. 8C-E). Without additives, full-length KIF16B bound to MTs less than KIF16B810 or KIF16B810-PX, whereas in the presence of AMP-PNP, all three proteins exhibited a similar binding ability. Our negative control, Myosin Vb, did not bind to MTs (Fig. $8 C-E$ ). Therefore, the cosedimentation assay results suggest that the second and third coiled-coil domains inhibit binding of KIF16B to microtubules in the presence of ATP.

Next, we examined the microtubule binding ability of KIF16B in living neurons. Cultured hippocampal neurons were transfected with KIF16BFull-GFP or KIF16B810-PX-GFP. To visualize the microtubule-bound population, transfected cells were transiently permeabilized with the bacterial toxin streptolysin-O, which is a membrane-damaging protein toxin that creates transient pores in cell membranes by binding to the cholesterolcontaining target membranes. Washing removed those proteins not bound to MTs from the cytoplasm. After $10 \mathrm{~min}$, the neurons were monitored using a special $\mathrm{BiG}(\mathrm{GaAsP})$ detector attached to a LSM710 Duo laser scanning confocal microscope. KIF16BFullGFP displayed a filamentous distribution pattern in the dendrites, suggesting that it was bound to dendritic MTs (Fig. 9A). In contrast, KIF16B810-PX-GFP showed a weak and diffuse signal

\section{$\leftarrow$}

Figure 6. Second and third coiled-coils of the KIF16B stalk domain are critical for the somatodendritic localization of KIF16B. $\boldsymbol{A}$, Schematic representation of the deletion and chimera mutants. $\boldsymbol{B}-\boldsymbol{J}$, Hippocampal neurons were transfected with the indicated constructs, cultured for 10-12 h, fixed, and then stained with a dendrite marker (MAP2) and a neuronal marker (tubulin- $\beta 3$ ). $\boldsymbol{B}$, Representative image of a mutant lacking the third coiled-coil (KIF16B936) that accumulated at axon tips. C, KIF16B810-GFP lacking the second and third coiled-coils localizes in the tips of axons. $\boldsymbol{B}, \boldsymbol{C}$, Enlarged merged insets and arrows indicate axonal tips as revealed with only tubulin- $\beta 3$ staining. D, A shorter $4 \mathrm{~h}$ expression of KIF16B810 mutant also results in diffuse expression in dendrites and specific localization at axon tips. $\boldsymbol{E}$, Ratio of axonal tips per axonal shafts signal intensity for the KIF16B810, KIF16B936, and controls (KIF16BFull and GFP). F, KIF16B810-PX-GFP is localized to axonal shafts and axonal tips. G, Chimera (KIF5C560-KIF16BPX-GFP) shows a similar localization pattern in axonal shafts and tips. $\boldsymbol{F}, \mathbf{G}$, High-magnification merges and arrows indicate axonal localization as revealed with only tubulin- $\beta 3$ staining. Dendrites are labeled with MAP2. Scale bars, $10 \mu \mathrm{m}$. $\boldsymbol{H}-\boldsymbol{J}$, Quantifications of KIF16B810-PX, chimera, and controls (KIF16BFull and GFP). $\boldsymbol{H}$, Relative axonal fluorescence intensity normalized to their background signals. I, Arbitrary units of axons per dendrites. $J$, Axonal density of the protein of interest per axonal density of GFP control. Data are mean \pm SD. Twenty-one neurons from three independent transfections were examined. ${ }^{* *} p<0.001(\boldsymbol{E}$, Student's t test; ANOVA and post hoc test). n.s., Not significant. Signal intensity and density were analyzed using ImageJ software. in the dendrites, along with a relatively strong dotty signal in axons, especially at the axonal tips (Fig. 9B-D). Together, these in vivo results show that full-length KIF16B binds to dendritic microtubules, and that, lacking the second and third coiled-coils, KIF16B810-PX-GFP is missorted to the axonal tips.

\section{Binding between the motor domain and the inhibitory domain}

Previous studies have shown that the activity of some KIFs is controlled by an auto-inhibitory mechanism, in which the tail domain associates directly with its motor domain and suppresses motility when cargoes are not bound to the tail domain (Nakata and Hirokawa, 2003; Verhey and Hammond, 2009; Nakata et al., 2011). Thus, to gain insight into the molecular mechanisms underlying the inhibition mediated by the second and third coiledcoil domains, we used a coimmunoprecipitation assay to test whether these coiled-coils (ID) of the stalk region of KIF16B could bind directly to the motor domain to inhibit its activity. Using this assay, we found that the ID binds directly to the motor domain of KIF16B (Fig. 10 A, C). We also examined whether the motor domain interacts with the PX domain. We observed no binding between the motor and PX domains of KIF16B, as expected based on previous results (Fig. $10 B, C$ ). To analyze the role of the ID within the cell, we overexpressed the ID in COS-7 cells and hippocampal neurons. In COS-7 cells that were transfected with the GFP control, EEA1 staining was evenly distributed throughout the cytoplasm and in the somatodendritic regions of neurons, with an even distribution of puncta. When the ID was expressed, the endosomes accumulated in the center of COS-7 cells; and in hippocampal neurons, the EEs tended to aggregate in the somatodendritic regions (Fig. 10D-G). We further conducted live imaging to test whether the ID affected the motility of KIF16B or EEs in neurons. Cotransfection of GFP-2xFYVE with the ID in neurons disturbed the motility of EEs in the somatodendritic regions compared with that in controls (the percentage of motile EEs: control, $81 \%$, + ID, 29\%; Fig. $10 H-L)$. These cell culture results, together with the coimmunoprecipitation data, indicate that the ID binds to the motor domain and suppresses the motility of KIF16B and the EEs.

The microtubule cosedimentation assay findings suggested that the inhibition of the binding of KIF16B to microtubules is regulated by ATP (Fig. $8 C-E$ ). Consequently, it is possible that the binding between the ID and the motor domain may also depend on ATP. To test this hypothesis, we examined the binding of a GST-tagged ID to a GFP-tagged motor domain, the PX domain, or full-length KIF16B using affinity chromatography. The motor domain and full-length KIF16B were able to bind to the ID in the presence of ATP but not in the presence of AMP-PNP, whereas the PX domain did not bind to the ID (Fig. 10M-O). Consistent with the results of the cosedimentation assay, fulllength KIF16B showed slightly weaker binding to the ID compared with the motor domain in the presence of ATP. Therefore, our data suggest that ATP regulates not only the inhibition of binding of KIF16B to microtubules, but also binding of the ID to the motor domain of KIF16B.

\section{Discussion}

Impact of KIF16B on EE and receptor trafficking in neurons We examined the role of KIF16B in the transport of EEs in neurons. Our results revealed that KIF16B transports EEs in somatodendritic regions. When KIF16B is knocked down, the bidirectional movements of EEs are perturbed, and they accumulate in the cell body and dendrites. This phenotype was rescued by 
A 1

1266
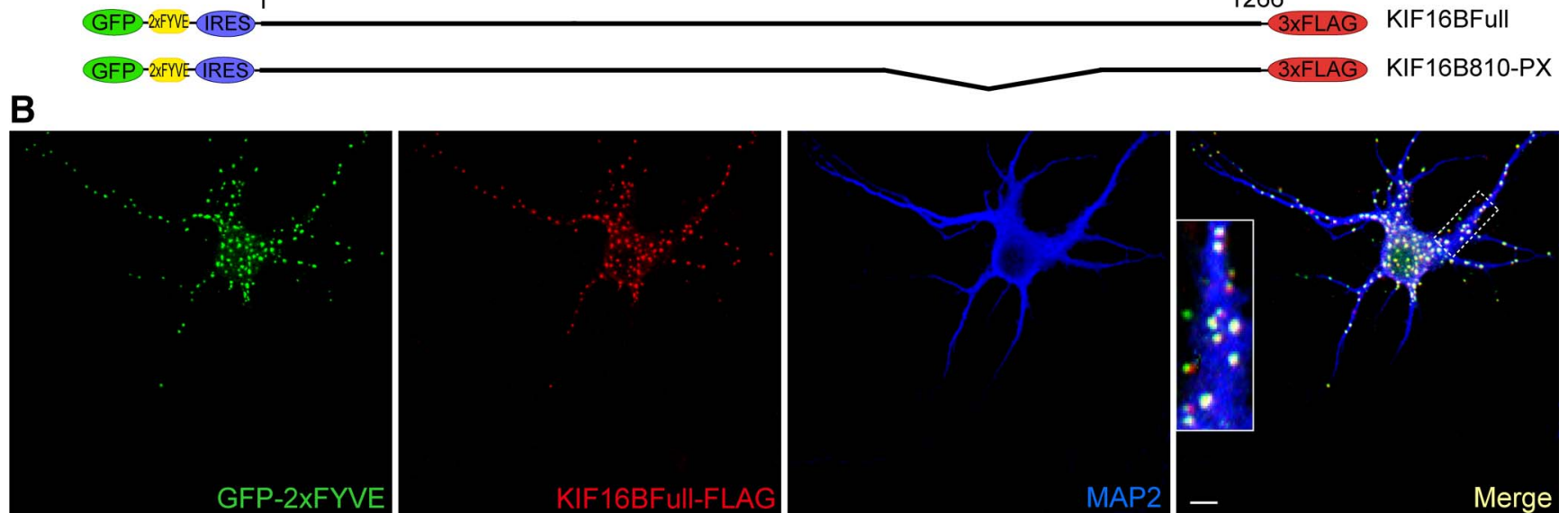

C
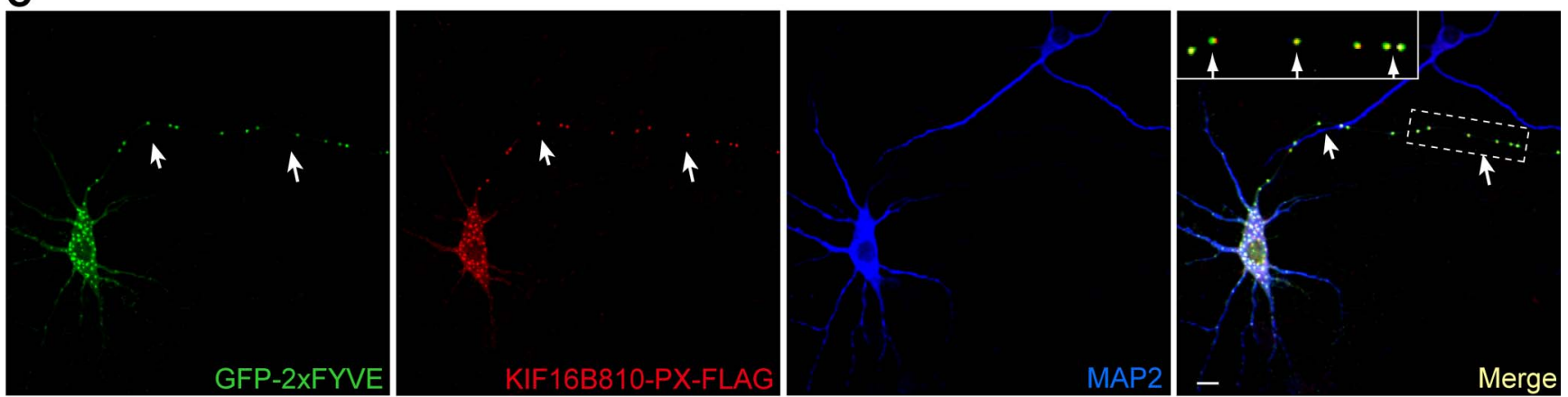

D
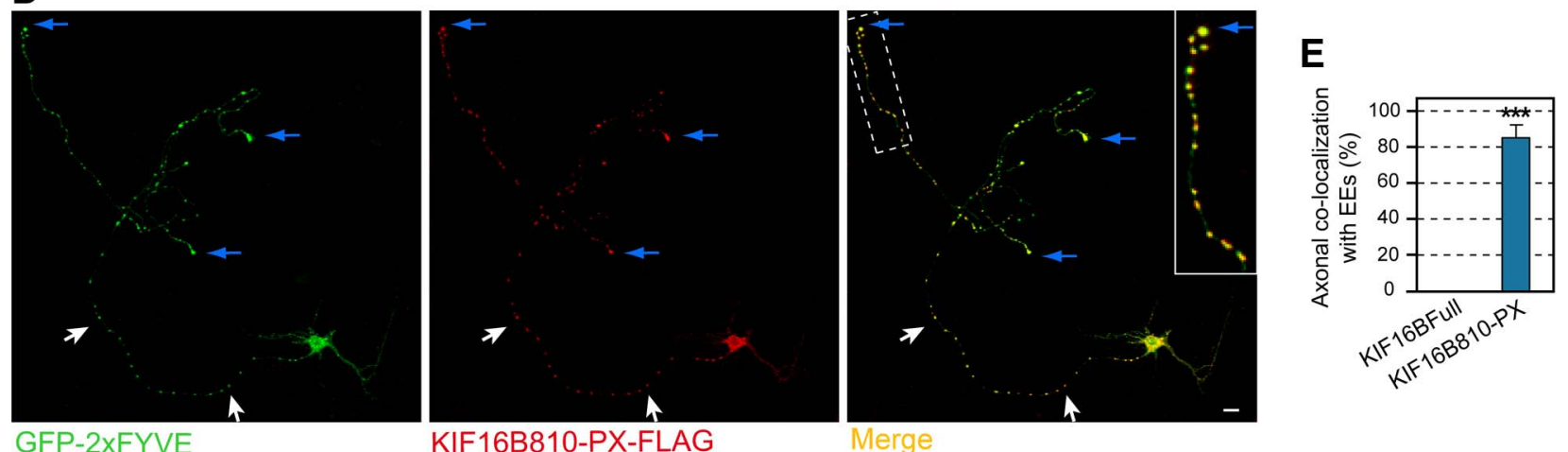

GFP-2xFYVE

KIF16B810-PX-FLAG

Merge

Figure 7. Second and third coiled-coils of the KIF16B stalk domain potentiate the somatodendritic localization of early endosomes. $A-E$, The indicated IRES-containing constructs were expressed in hippocampal neurons, which were cultured for $10-12 \mathrm{~h}$, fixed and immunostained with anti-MAP2 antibody (blue). Localization of EEs was revealed by GFP-2xFYVE in KIF16BFull-FLAG control $(\boldsymbol{B})$ and in KIF16B810-PX-FLAG-transfected neurons (C, D). D, Lower-magnification image showing that both GFP-2xFYVE and KIF16B810-PX-FLAG misaccumulated at axonal tips. Insets (of dotted areas), Colocalization of EEs with KIF16BFull in somatodendritic regions of $\boldsymbol{B}$ and KIF16B810-PX along the axon in $\boldsymbol{C}$ and distal axon in $\boldsymbol{D}$. White arrows indicate the axonal shafts. Blue arrows indicate axonal tips. Scale bars, $10 \mu \mathrm{m}$. E, Percentage of the axonal colocalization of KIF16BFull (control) and KIF16B810-PX with EEs was quantified with a pixel-by-pixel correlation between green and red signals using ImageJ software. This revealed a significant mislocalization of the EEs with KIF16B810-PX along the axons and tips. Error bars indicate mean \pm SD. Twenty-one neurons from three independent preparations were examined. ${ }^{* *} p<0.001$ (Student's $t$ test).

KIF16B expression. Our results suggest that the normal activity of KIF16B keeps the EEs moving properly and dispersed along the dendrites. The bidirectional motion of EEs and KIF16B is consistent with the bidirectional arrangement of MTs in somatodendritic regions. Considering that KIF16B knockdown has the same effect on the motility of EEs in both anterograde and retrograde directions, we suggest that, relative to MTs, velocity distribution is independent of direction and may depend on cargoes carried in EEs and/or on associated proteins (Gasman et al., 2003). We found that disruption of the PX domain abrogates the binding of KIF16B to EE. However, expression of the PX domain on its own results in a phenotype resembling the wild-type endosomal pat- tern, suggesting that the PX domain of KIF16B is the cargobinding domain.

Previous studies have proposed that EEs can acquire and recycle cargo to the cell membrane as long as KIF16B keeps them near the surface of HeLa cells (Lin et al., 2002; Hoepfner et al., 2005). EEs also contribute to the somatodendritic and axonal localization of receptors by participating in somatodendriticspecific endocytosis, recycling, and transcytosis processes that lead to the redistribution of receptors from dendrites to axons (Yap et al., 2008; Winckler and Mellman, 2010; Petersen et al., 2014). Here, we found that defects in KIF16B expression, and the corresponding EE motility, perturb the distribution of GluR1 

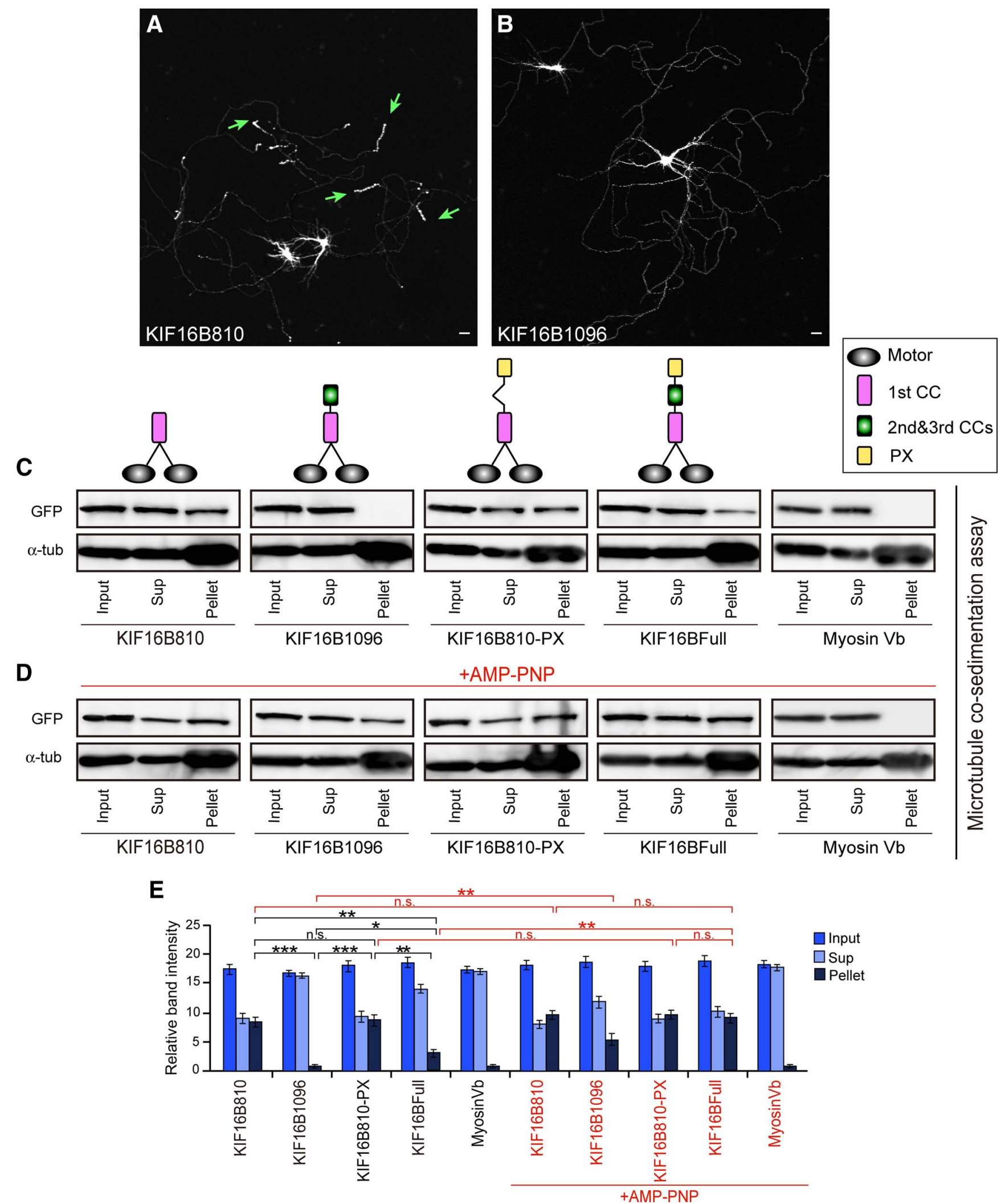

Figure 8. Second and third coiled-coils of KIF16B function as an inhibitory domain. $A, B$, Localization of KIF16B mutants in hippocampal neurons stained with MAP2 and tubulin- $\beta 3$. KIF16B810GFP is localized at tips of axons, whereas KIF16B1096-GFP shows diffuse localization. Arrows indicate tips of axons. MAP2 and tubulin- $\beta 3$ images are not shown here because of the interference with the grayscale images. Scale bars, $10 \mu \mathrm{m}$. Representative images from 21 neurons obtained from three independent preparations are shown. $\mathbf{C}-\boldsymbol{E}$, Microtubule cosedimentation assay. $\boldsymbol{C}, \boldsymbol{D}, \mathbf{C O S}-7$ cells were transfected with KIF16B810, KIF16B1096, KIF16B810-PX, KIF16BFull, or myosin Vb, tagged with GFP, Iysed, mixed with tubulin, incubated at $37^{\circ} \mathrm{C}$, and centrifuged to separate cytosolic and microtubule pellet fractions. $C$, In the absence of AMP-PNP. $\boldsymbol{D}$, In the presence of AMP-PNP. Western blot analysis was performed with anti-GFP and anti- $\alpha$-tubulin antibodies. Myosin Vb was used as a negative control. $\boldsymbol{E}$, Quantification of relative band intensities corresponding to the Western blots in $\boldsymbol{C}, \boldsymbol{D}$ was performed using ImageJ software. Error bars indicate SD. Four individual experiments were conducted for each value. ${ }^{*} p<0.05$ (ANOVA and post hoc test). ${ }^{* *} p<0.01$ (ANOVA and post hoc test). ${ }^{* * *} p<0.001$ (ANOVA and post hoc test). n.s., Not significant. 

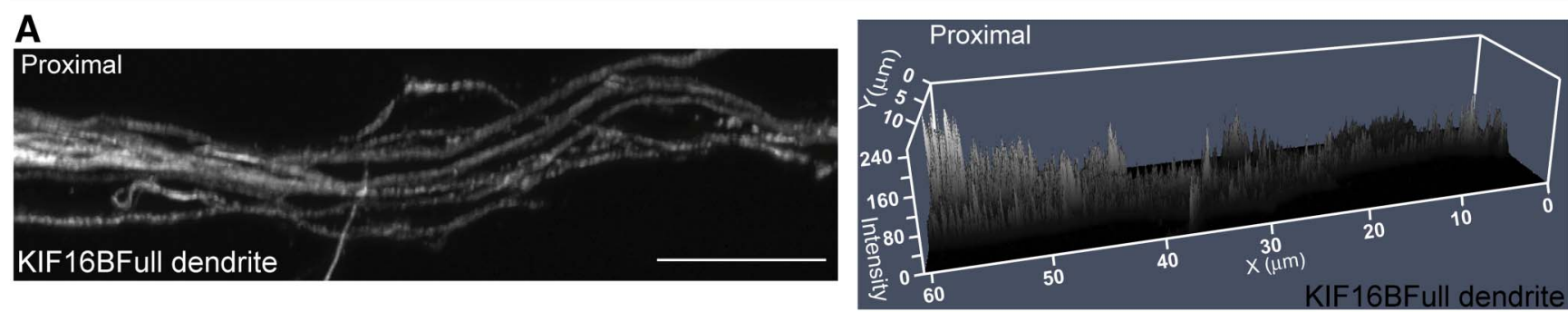

\section{B}
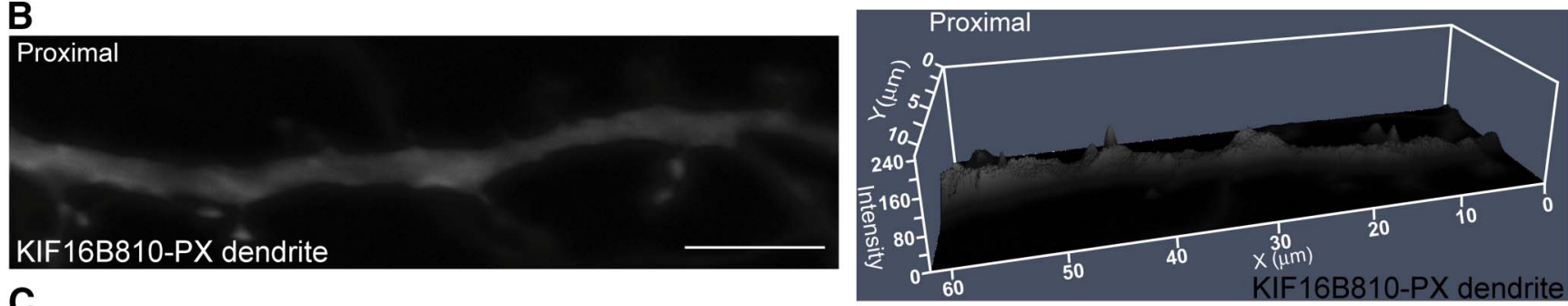

\section{C}
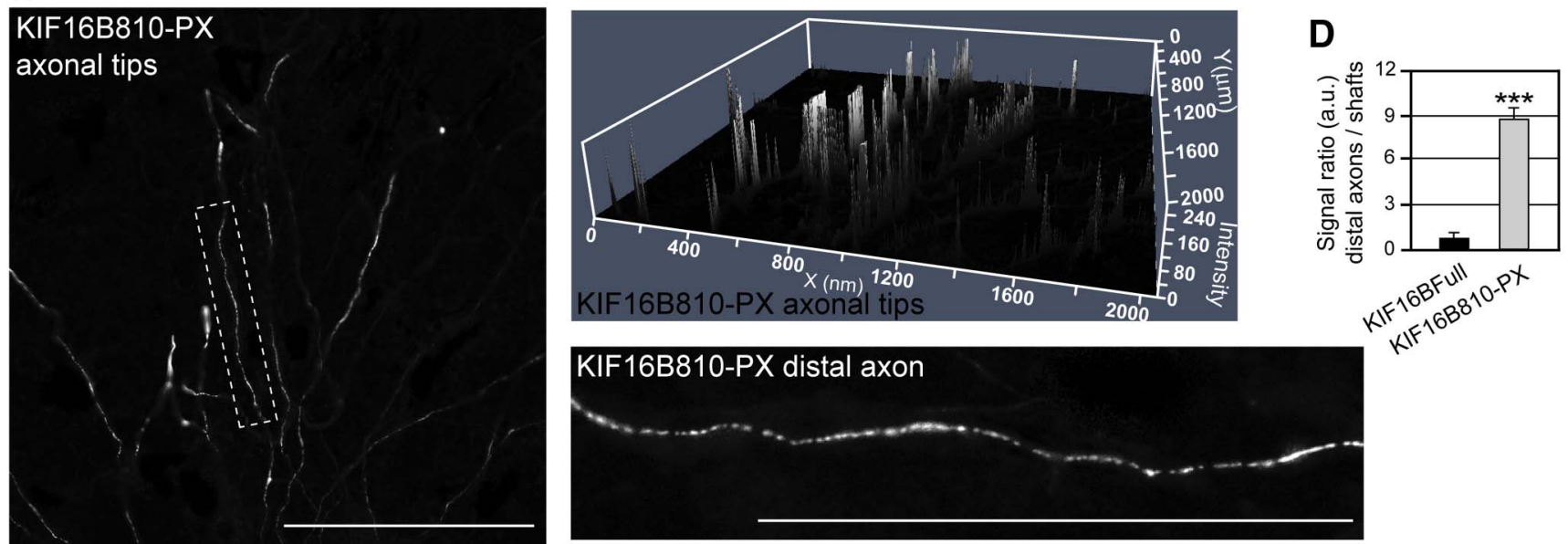

Figure 9. KIF16B binds to dendritic microtubules. A-D, Live neuron microtubule binding assay. Neurons, expressing KIF16B GFP-tagged constructs for $10-12 \mathrm{~h}$, were transiently permeabilized with streptolysin- 0 and monitored after 10 min using a laser scanning confocal microscope equipped with a special detector. $A$, Neuron expressing KIF16BFull shows microtubule pattern along the dendrite. Right, 3D profile of the fluorescence intensity along the dendrite showing dotty signals. B, C, Neuron expressing KIF16B810-PX. B, Weak and diffuse signals along the dendrite. Right, 3D profile of the fluorescence intensity along the dendrite also indicates weak and diffuse signal. C, Strong signals in axonal tips. Right top, $3 D$ profile of the fluorescence intensity in the distal axons and axonal tips presenting dotty signals. Right bottom, Magnification of the distal portion of the axon. Scale bars, $10 \mu \mathrm{m}$. 3D fluorescence profiles were obtained using Carl Zeiss LSM image software. $D$, Statistical analysis of signal ratio of distal axons per axon shafts for KIF16B810-PX and KIF16BFull. Images were quantified with ImageJ software. Data are mean \pm SD. Fifteen neurons from three independent transfections were examined. ${ }^{* *} p<0.001$ (Student's $t$ test).

and $\mathrm{p} 75^{\mathrm{NTR}}$ in neurons. The electrophysiological function of AMPA receptors, critical for neuronal plasticity, was consistently impaired (Whitlock et al., 2006; Shepherd and Huganir, 2007; Kessels and Malinow, 2009). Moreover, surface expression of these receptors was reduced, resulting in decreased amplitude and increased interevent interval of mEPSCs in KIF16B knockdown neurons. These results revealed that KIF16B is important for surface localization of GluR1 and $\mathrm{p} 75^{\mathrm{NTR}}$. KIF16B may be involved in regulating trafficking of many functionally important receptors through its activity in transporting EEs in somatodendritic areas. Collectively, our findings indicate a functional significance of KIF16B in EE transport and receptor trafficking in cell bodies and dendrites of neurons.

New regulatory mechanism potentiates the selective distribution of KIF16B and EEs

Our findings show that KIF16B and its cargo of EEs are specifically localized in somatodendritic regions of neurons. KIFs are key regulators that determine the destination of cargo proteins.
Previous studies elucidated several mechanisms that determine the localization of molecular motors and showed that the motor domain determines the distribution of KIFs (Nakata and Hirokawa, 2007; Nakata et al., 2011; Huang and Banker, 2012). Some motors specifically travel in axons, whereas others move in axons and dendrites. It has been suggested that cargo-binding affects the localization of some motors (Setou et al., 2002; Hoogenraad et al., 2005; Jenkins et al., 2012). We show here, for the first time, that the stalk domain of a kinesin has the capacity to potentiate the particular localization of that motor protein and its cargo.

The cargo-binding domains of some KIFs bind directly to the motor domain and inhibit motor activity when unbound to cargo (Verhey and Hammond, 2009). This mechanism is called "tail-inhibition." In addition to this mechanism, we suggest a new "stalk inhibition" mechanism. Deleting the second and third coiled-coils of the KIF16B stalk domain mislocalized KIF16B (Fig. 6). Furthermore, although the wild-type KIF16B was precisely localized in somatodendritic regions, KIF16B missing the 


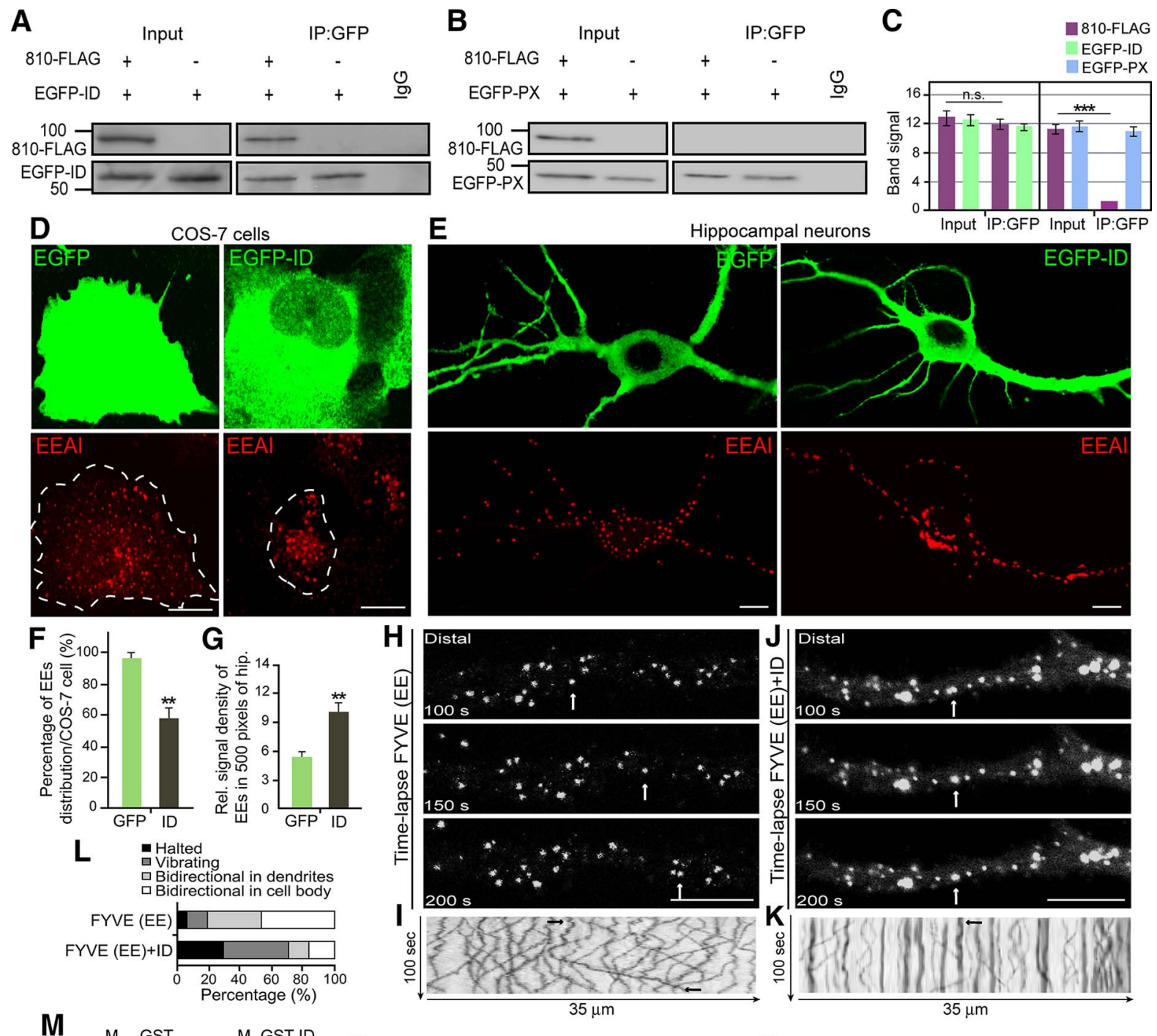

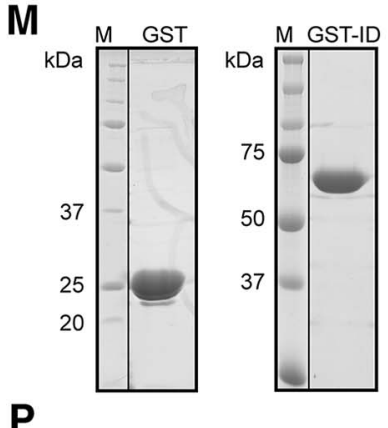

Stalk inhibited
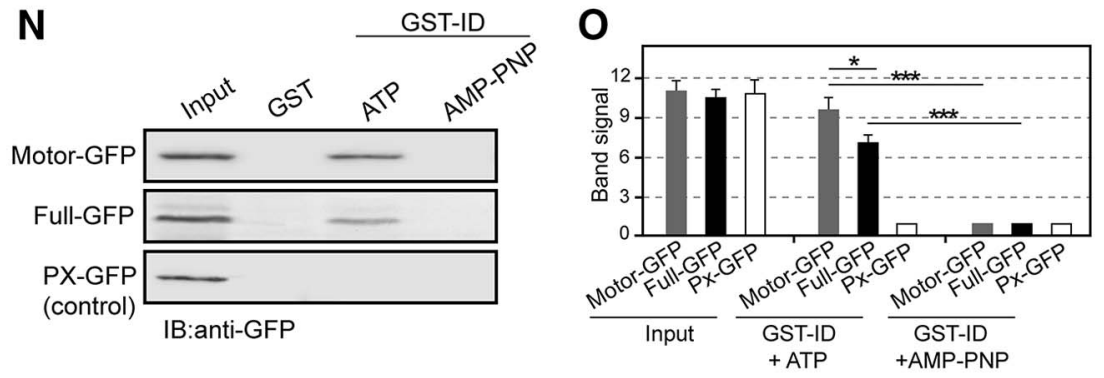

Uninhibited model (somatodendritic regions)
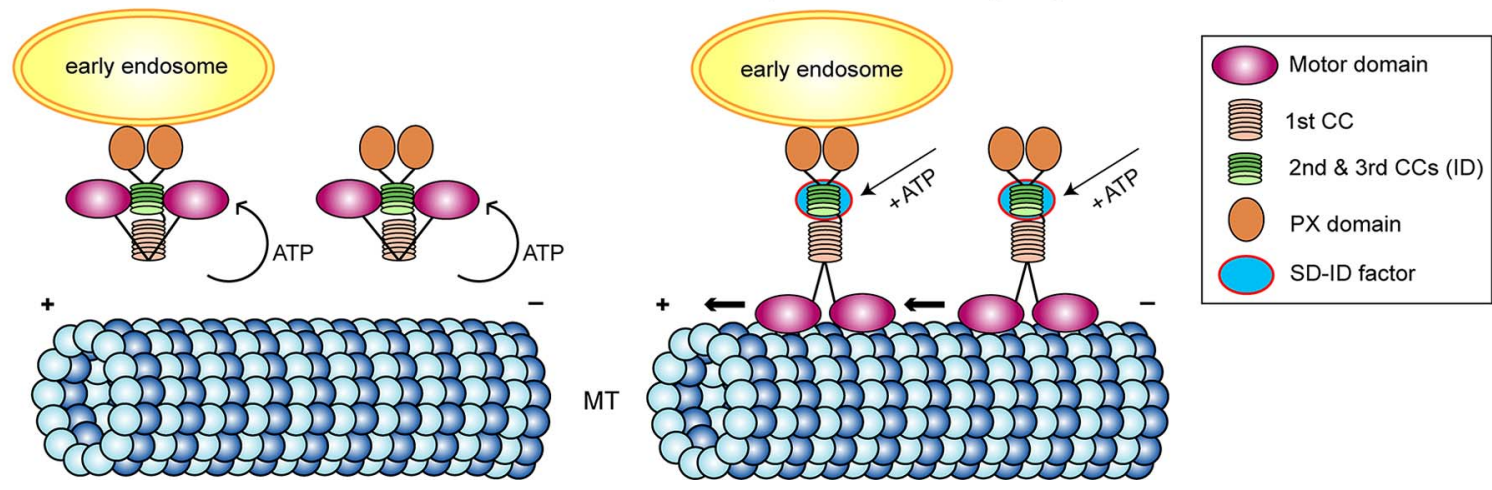
second and third coiled-coils and its cargo of EEs accumulated specifically in the tips of axons (Figs. 7 and 9). Biochemical and cell biological assays revealed that the second and third coiledcoils bound directly to the motor domain and inhibited the attachment of the motor with MTs in an ATP-dependent manner (Figs. 8 and 10). These results suggest that the motor activity of KIF16B is negatively regulated by the second and third coiled-coil domains (i.e., the ID). The requirement of ATP for stalk inhibition in KIF16B is similar to that of the kinesin-5 tail-inhibition mechanism. The IAK region of KIF5 inhibits the ATPase activity of the kinesin, resulting in a weak affinity for MTs in the presence of ATP. This arises from the selective inhibition of the release of ADP upon the initial interaction with an MT (the ADP state of the head is "turned off") (Hackney and Stock, 2000). Thus, the two coiled-coil sections of the stalk are essential for the KIF16B autoregulatory mechanism that inhibits microtubule binding in the presence of ATP.

The mechanisms by which organelles are sorted are unclear. Some cargoes are directly sorted to axons after modification in the Golgi apparatus (Nakata and Hirokawa, 2003), and a diffusion barrier at the axon initial segment keeps dendritic proteins from mislocalizing to axons (Song et al., 2009). In addition, the molecular mechanisms determining the somatodendritic localization of EEs remain unknown. Previous studies have shown that cargo transport is regulated by the association and dissociation of motors (Bridgman, 1999; Guillaud et al., 2008; Macaskill et al., 2009, Wang and Schwarz, 2009; Jenkins et al., 2012). However, our results suggest that the association of the PX domain of KIF16B with EEs is not inhibited in axons because the expression of KIF16B810-PXGFP (KIF16B $\Delta$ ID), which possesses the ability to associate with EEs, missorts both to axonal tips. This suggests that the localization of EEs is not controlled by the association and

$\leftarrow$

Figure 10. Motor domain of KIF16B binds to the inhibitory domain. $A-C$, Coimmunoprecipitations of the motor domain with the second and third coiled-coils (ID) of the KIF16B stalk region $(\boldsymbol{A})$ and the PX domain of KIF16B $(\boldsymbol{B})$. Proteins were transfected and precipitated with an anti-GFP antibody. Western blot analysis of input and pellet fractions was performed using anti-GFP and anti-FLAG antibodies. A representative blot is shown. C, Quantification of Western blotting band signals for the coimmunoprecipitations. $D-L$, The inhibitory domain disrupts the movements of KIF16B and the EES. D-F, EGFP or EGFP-ID were transfected into COS-7 cells (D) and hippocampal neurons $(\boldsymbol{E})$, which were stained with anti-EEA1 and, for neurons, also with MAP2. $\boldsymbol{F}$, Percentage of EEs distribution per COS-7 cells. G, Relative signal density of EEs in 500 pixels of hippocampal neurons (hip.). Quantifications revealed the accumulation of EEs in cells expressing the ID compared with control. Distribution and density measured with ImageJ software. $\boldsymbol{H}-\boldsymbol{L}$, Analysis of EE movements in the presence or absence of the ID. Time-lapse images $(\boldsymbol{H})$ and kymograph $(\boldsymbol{I})$ of the control neuron that expressed the EE marker, FYVE, and shows bidirectional movement of $\mathrm{EEs}$ along the dendrite. Arrows indicate an example of a moving $\mathrm{EE}$. Time-lapse images $(\boldsymbol{J})$ and kymograph $(\boldsymbol{K})$ of the neuron that was cotransfected with ID and FYVE displays significantly reduced bidirectional movement of the EEs along the dendrite. Arrows point to an example of a stalled EE. Scale bars, $10 \mu \mathrm{m}$. $L$, Classification of motility. $p<$ 0.001. M-O, GST affinity chromatography analysis for interactions between GST-ID with KIF16B fragments tagged with GFP. $M$, Coomassie blue-stained gels indicating the level of GST and GST-inhibitory domain on the beads. $\boldsymbol{N}$, GST pull-down assay between GST and GST-ID with KIF16B810-GFP (motor domain), full-length KIF16B, and KIF16BPX as a control in the presence of ATP or AMP-PNP. 0, Statistical analysis of Western blotting results in the GST pull-down assay. For all statistical analyses, error bars indicate mean $\pm S D$ from three independent experiments. A total of 18 COS-7 cells $(\boldsymbol{F})$ and 18 neurons $(\boldsymbol{G}, \boldsymbol{L})$ were analyzed. $\boldsymbol{C}, \mathbf{O}, n=3$. n.s., Not significant. ${ }^{*} p<0.05$ (Student'sttest). ${ }^{* *} p<0.01$ (Student'st test). ${ }^{* * *} p<0.001$ (Student's $t$ test). $L, \chi^{2}$ test. $P$, Diagram model summarizing the "stalk inhibition" regulatory mechanism. KIF16B binding to MTs is suppressed by the interaction of the second and third coiled-coils of the stalk domain (ID) and motor domain in the presence of ATP. KIF16B moves on MTs and transports early endosomes in somatodendritic regions as long as the SD-ID factor is associated with the ID in an ATP-dependent system and represses motor and ID interaction. dissociation of KIF16B with EEs, but rather by an intramolecular regulatory mechanism.

Disruption of the stalk inhibition mechanism mislocalizes KIF16B into axons, and KIF16B motor-containing constructs without complete ID and PX domains also show axonal mislocalization. This suggests that the motor domain itself has a tendency to localize in axons. In wild-type neurons, the presence of the ID and stalk inhibition mechanism prevent the motor from being distributed in areas of the neuron not requiring the motor (i.e., the axon) and, as a result, potentiate proper somatodendritic localization of KIF16B and EEs. Our data suggest that stalk inhibition is turned off in the cell body and dendrites, which leads one to question why stalk inhibition does not function in somatodendritic regions. Because wild-type KIF16B-carrying EEs do not enter the axon but travel in somatodendritic areas, it is unlikely that the binding of EE to the PX domain of KIF16B represses the ID/motor domain interaction and turns on the motor. Given our data for the diffuse distribution of KIF16B1096 and KIF16BPXmut throughout the neuron as well as our data showing that the ID disturbs the motility of the motor in somatodendritic regions, it is likely that the binding of the ID and motor domain occurs throughout the neuron, making it improbable that an axon-specific factor exists to enhance the ID/motor interaction and switch off the motor in axons. Thus, because functional KIF16B moves along MTs and transports EEs in somatodendritic regions and because the presence of the ID is necessary for this selective localization, we propose the presence of a somatodendritic-specific factor (SD-ID factor) that binds to the ID, turns off stalk inhibition, and triggers KIF16B movement along MTs in somatodendritic areas (Fig. 10P). Considering the pull-down assay result, we conjecture that the association of an SD-ID factor with the ID is regulated by an ATP-dependent system. Kinesin-associated proteins are known to regulate the activity of a variety of KIFs. Consequently, this SD-ID factor is likely an ID-associated protein located in somatodendritic regions. Further biochemical studies are needed to determine the identity of this factor.

Considering that KIF16B1096 and KIF16BPXmut, which were unable to bind to EEs, were diffusely localized throughout the neuron, the binding of EE to KIF16B may spatially strengthen the SD-ID/ID interaction. The SD-ID/ID interaction suppresses stalk inhibition, enabling KIF16B to move along MTs in somatodendritic regions. Additionally, full-length KIF16B displayed a weak affinity for MTs in the cosedimentation assay and weaker binding to the ID in the pull-down assay. This suggests that, as no direct attachment was detected between the PX and motor domains or ID, the presence of the PX domain may reduce the interaction of the motor domain with the ID, thereby bringing the ID into contact with the SD-ID factor and allowing movement along MTs. Therefore, in wild-type KIF16B, the presence of the PX domain and the binding of EE to the PX domain presumably enhance the association of SD-ID factor with the ID.

This study presented a novel "stalk inhibition" mechanism that regulates the potential of KIF16B to determine the selective localization of this motor protein and its EE cargo in somatodendritic regions of neurons. The interaction between the stalk inhibitory and motor domains may serve as a switch to control the binding of the KIF16B motor to microtubules. Our proposed SD-ID factor suppresses stalk inhibition by associating with the ID in somatodendritic regions, resulting in movement along microtubules. 


\section{References}

Bielska E, Schuster M, Roger Y, Berepiki A, Soanes DM, Talbot NJ, Steinberg G (2014) Hook is an adapter that coordinates kinesin-3 and dynein cargo attachment on early endosomes. J Cell Biol 204:989-1007. CrossRef Medline

Blatner NR, Wilson MI, Lei C, Hong W, Murray D, Williams RL, Cho W (2007) The structural basis of novel endosome anchoring activity of KIF16B kinesin. EMBO J 26:3709-3719. CrossRef Medline

Bridgman PC (1999) Myosin Va movements in normal and dilute-lethal axons provide support for a dual filament motor complex. J Cell Biol 146:1045-1060. CrossRef Medline

Burd CG, Emr SD (1998) Phosphatidylinositol(3)-phosphate signaling mediated by specific binding to RING FYVE domains. Mol Cell 2:157-162. CrossRef Medline

Cai Q, Gerwin C, Sheng ZH (2005) Syntabulin-mediated anterograde transport of mitochondria along neuronal processes. J Cell Biol 170:959-969. CrossRef Medline

Ellson CD, Anderson KE, Morgan G, Chilvers ER, Lipp P, Stephens LR, Hawkins PT (2001) Phosphatidylinositol 3-phosphate is generated in phagosomal membranes. Curr Biol 11:1631-1635. CrossRef Medline

Gasman S, Kalaidzidis Y, Zerial M (2003) RhoD regulates endosome dynamics through Diaphanous-related Formin and Src tyrosine kinase. Nat Cell Biol 5:195-204. CrossRef Medline

Gerdes JM, Davis EE, Katsanis N (2009) The vertebrate primary cilium in development, homeostasis, and disease. Cell 137:32-45. CrossRef Medline

Glater EE, Megeath LJ, Stowers RS, Schwarz TL (2006) Axonal transport of mitochondria requires milton to recruit kinesin heavy chain and is light chain independent. J Cell Biol 173:545-557. CrossRef Medline

Guillaud L, Wong R, Hirokawa N (2008) Disruption of KIF17-Mint1 interaction by CaMKII-dependent phosphorylation: a molecular model of kinesin-cargo release. Nat Cell Biol 10:19-29. CrossRef Medline

Hackney DD, Stock MF (2000) Kinesin's IAK tail domain inhibits initial microtubule-stimulated ADP release. Nat Cell Biol 2:257-260. CrossRef Medline

Hirokawa N, Niwa S, Tanaka Y (2010) Molecular motors in neurons: transport mechanisms and roles in brain function, development, and disease. Neuron 68:610-638. CrossRef Medline

Hoepfner S, Severin F, Cabezas A, Habermann B, Runge A, Gillooly D, Stenmark H, Zerial M (2005) Modulation of receptor recycling and degradation by the endosomal kinesin KIF16B. Cell 121:437-450. CrossRef Medline

Hoogenraad CC, Milstein AD, Ethell IM, Henkemeyer M, Sheng M (2005) GRIP1 controls dendrite morphogenesis by regulating EphB receptor trafficking. Nat Neurosci 8:906-915. CrossRef Medline

Hoogenraad CC, Popa I, Futai K, Martinez-Sanchez E, Sanchez-Martinez E, Wulf PS, van Vlijmen T, Dortland BR, Oorschot V, Govers R, Monti M, Heck AJ, Sheng M, Klumperman J, Rehmann H, Jaarsma D, Kapitein LC, van der Sluijs P (2010) Neuron specific Rab4 effector GRASP-1 coordinates membrane specialization and maturation of recycling endosomes. PLoS Biol 8:e1000283. CrossRef Medline

Hoopmann P, Punge A, Barysch SV, Westphal V, Bückers J, Opazo F, Bethani I, Lauterbach MA, Hell SW, Rizzoli SO (2010) Endosomal sorting of readily releasable synaptic vesicles. Proc Natl Acad Sci U S A 07:1905519060. CrossRef Medline

Huang CF, Banker G (2012) The translocation selectivity of the kinesins that mediate neuronal organelle transport. Traffic 13:549-564. CrossRef Medline

Jacobson C, Schnapp B, Banker GA (2006) A change in the selective translocation of the Kinesin-1 motor domain marks the initial specification of the axon. Neuron 49:797-804. CrossRef Medline

Jenkins B, Decker H, Bentley M, Luisi J, Banker G (2012) A novel split kinesin assay identifies motor proteins that interact with distinct vesicle populations. J Cell Biol 198:749-761. CrossRef Medline

Jiang M, Chen G (2006) High $\mathrm{Ca}^{2+}$-phosphate transfection efficiency in low-density neuronal cultures. Nat Protoc 1:695-700. CrossRef Medline

Kanai Y, Dohmae N, Hirokawa N (2004) Kinesin transports RNA: isolation and characterization of an RNA-transporting granule. Neuron 43:513525. CrossRef Medline

Kessels HW, Malinow R (2009) Synaptic AMPA receptor plasticity and behavior. Neuron 61:340-350. CrossRef Medline

Komada M, Soriano P (1999) Hrs, a FYVE finger protein localized to early endosomes, is implicated in vesicular traffic and required for ventral folding morphogenesis. Genes Dev 13:1475-1485. CrossRef Medline

Kondo S, Sato-Yoshitake R, Noda Y, Aizawa H, Nakata T, Matsuura Y, Hirokawa N (1994) KIF3A is a new microtubule-based anterograde motor in the nerve axon. J Cell Biol 125:1095-1107. CrossRef Medline

Lasiecka ZM, Yap CC, Caplan S, Winckler B (2010) Neuronal early endosomes require EHD1 for L1/NgCAM trafficking. J Neurosci 30:1648516497. CrossRef Medline

Lin SX, Gundersen GG, Maxfield FR (2002) Export from pericentriolar endocytic recycling compartment to cell surface depends on stable, detyrosinated (glu) microtubules and kinesin. Mol Biol Cell 13:96-109. CrossRef Medline

Macaskill AF, Rinholm JE, Twelvetrees AE, Arancibia-Carcamo IL, Muir J, Fransson A, Aspenstrom P, Attwell D, Kittler JT (2009) Mirol is a calcium sensor for glutamate receptor-dependent localization of mitochondria at synapses. Neuron 61:541-555. CrossRef Medline

Nakata T, Hirokawa N (2003) Microtubules provide directional cues for polarized axonal transport through interaction with kinesin motor head. J Cell Biol 162:1045-1055. CrossRef Medline

Nakata T, Hirokawa N (2007) Neuronal polarity and the kinesin superfamily proteins. Sci STKE 2007:pe6. CrossRef Medline

Nakata T, Niwa S, Okada Y, Perez F, Hirokawa N (2011) Preferential binding of a kinesin-1 motor to GTP-tubulin-rich microtubules underlies polarized vesicle transport. J Cell Biol 194:245-255. CrossRef Medline

Nangaku M, Sato-Yoshitake R, Okada Y, Noda Y, Takemura R, Yamazaki H, Hirokawa N (1994) KIF1B, a novel microtubule plus end-directed monomeric motor protein for transport of mitochondria. Cell 79:12091220. CrossRef Medline

Nicholls JG (2001) From neuron to brain, Ed 4. Sunderland, MA: Sinauer.

Nielsen E, Severin F, Backer JM, Hyman AA, Zerial M (1999) Rab5 regulates motility of early endosomes on microtubules. Nat Cell Biol 1:376-382. CrossRef Medline

Niwa S, Tanaka Y, Hirokawa N (2008) KIF1B beta- and KIF1A-mediated axonal transport of presynaptic regulator Rab3 occurs in a GTPdependent manner through DENN/MADD. Nat Cell Biol 10:1269-1279. CrossRef Medline

Okada Y, Yamazaki H, Sekine-Aizawa Y, Hirokawa N (1995) The neuronspecific kinesin superfamily protein KIF1A is a unique monomeric motor for anterograde axonal transport of synaptic vesicle precursors. Cell 81: 769-780. CrossRef Medline

Perez Bay AE, Schreiner R, Mazzoni F, Carvajal-Gonzalez JM, Gravotta D, Perret E, Lehmann Mantaras G, Zhu YS, Rodriguez-Boulan EJ (2013) The kinesin KIF16B mediates apical transcytosis of transferrin receptor in AP-1B-deficient epithelia. EMBO J 32:2125-2139. CrossRef Medline

Petersen JD, Kaech S, Banker G (2014) Selective microtubule-based transport of dendritic membrane proteins arises in concert with axon specification. J Neurosci 34:4135-4147. CrossRef Medline

Salinas S, Bilsland LG, Schiavo G (2008) Molecular landmarks along the axonal route: axonal transport in health and disease. Curr Opin Cell Biol 20:445-453. CrossRef Medline

Sampo B, Kaech S, Kunz S, Banker G (2003) Two distinct mechanisms target membrane proteins to the axonal surface. Neuron 37:611-624. CrossRef Medline

Sarli V, Giannis A (2008) Targeting the kinesin spindle protein: basic principles and clinical implications. Clin Cancer Res 14:7583-7587. CrossRef Medline

Setou M, Nakagawa T, Seog DH, Hirokawa N (2000) Kinesin superfamily motor protein KIF17 and mLin-10 in NMDA receptor-containing vesicle transport. Science 288:1796-1802. CrossRef Medline

Setou M, Seog DH, Tanaka Y, Kanai Y, Takei Y, Kawagishi M, Hirokawa N (2002) Glutamate-receptor-interacting protein GRIP1 directly steers kinesin to dendrites. Nature 417:83-87. CrossRef Medline

Shepherd JD, Huganir RL (2007) The cell biology of synaptic plasticity: AMPA receptor trafficking. Annu Rev Cell Dev Biol 23:613-643. CrossRef Medline

Skjeldal FM, Strunze S, Bergeland T, Walseng E, Gregers TF, Bakke O (2012) The fusion of early endosomes induces molecular-motor-driven tubule formation and fission. J Cell Sci 125:1910-1919. CrossRef Medline

Song AH, Wang D, Chen G, Li Y, Luo J, Duan S, Poo MM (2009) A selective filter for cytoplasmic transport at the axon initial segment. Cell 136:1148 1160. CrossRef Medline

Soppina V, Norris SR, Dizaji AS, Kortus M, Veatch S, Peckham M, Verhey KJ 
(2014) Dimerization of mammalian kinesin-3 motors results in superprocessive motion. Proc Natl Acad Sci U S A 111:5562-5567. CrossRef Medline

Ueno H, Huang X, Tanaka Y, Hirokawa N (2011) KIF16B/Rab14 molecular motor complex is critical for early embryonic development by transporting FGF receptor. Dev Cell 20:60-71. CrossRef Medline

Vale RD (2003) The molecular motor toolbox for intracellular transport. Cell 112:467-480. CrossRef Medline

Verhey KJ, Hammond JW (2009) Traffic control: regulation of kinesin motors. Nat Rev Mol Cell Biol 10:765-777. CrossRef Medline

Wang X, Schwarz TL (2009) The mechanism of $\mathrm{Ca}^{2+}$-dependent regulation of kinesin-mediated mitochondrial motility. Cell 136:163-174. CrossRef Medline

Whitlock JR, Heynen AJ, Shuler MG, Bear MF (2006) Learning induces long-term potentiation in the hippocampus. Science 313:1093-1097. CrossRef Medline

Wilson JM, de Hoop M, Zorzi N, Toh BH, Dotti CG, Parton RG (2000) EEA1, a tethering protein of the early sorting endosome, shows a polar- ized distribution in hippocampal neurons, epithelial cells, and fibroblasts. Mol Biol Cell 11:2657-2671. CrossRef Medline

Winckler B, Mellman I (2010) Trafficking guidance receptors. Cold Spring Harb Perspect Biol 2:a001826. CrossRef Medline

Woo NH, Teng HK, Siao CJ, Chiaruttini C, Pang PT, Milner TA, Hempstead BL, Lu B (2005) Activation of p75NTR by proBDNF facilitates hippocampal long-term depression. Nat Neurosci 8:1069-1077. CrossRef Medline

Wood KW, Chua P, Sutton D, Jackson JR (2008) Centromere-associated protein E: a motor that puts the brakes on the mitotic checkpoint. Clin Cancer Res 14:7588-7592. CrossRef Medline

Yap CC, Wisco D, Kujala P, Lasiecka ZM, Cannon JT, Chang MC, Hirling H, Klumperman J, Winckler B (2008) The somatodendritic endosomal regulator NEEP21 facilitates axonal targeting of L1/NgCAM. J Cell Biol 180:827-842. CrossRef Medline

Zhao C, Takita J, Tanaka Y, Setou M, Nakagawa T, Takeda S, Yang HW, Terada S, Nakata T, Takei Y, Saito M, Tsuji S, Hayashi Y, Hirokawa N (2001) Charcot-Marie-Tooth disease type 2A caused by mutation in a microtubule motor KIF1B beta. Cell 105:587-597. CrossRef Medline 